\title{
Systematic tools for the conceptual design of inherently safer chemical processes
}

Rubén Ruiz-Femenia*, María. J. Fernández-Torres, Raquel Salcedo-Díaz, M. Francisca Gómez-Rico, JoséA. Caballero

Department of Chemical Engineering, University of Alicante. Ap. Correos 99, E- 03080, Alicante. Spain.

* Corr esponding author: Rubén Ruiz-Femenia

Department of Chemical Engineering, University of Alicante. Ap. Correos 99, E- 03080, Alicante. Spain. Tel: +34 965903400.

E-mail address: Ruben.Ruiz@uaes 


\section{ABSTRACT}

Society is continuously facing challenges for safer chemical plants design, which is usually driven by economic criteria during the early steps of the design process, relegating safety concerns to the latest stages. This paper highlights the synergy of merging Process System Engineering tools with inherent safety principles. Firstly, we design a superstructure that comprises several alternatives for streams, equipment and process conditions, which exhibit different performance of economic and inherently safer indicators, the total annualized cost and the DOW's Fire \& Explosion Index, respectively. The solution to this multi-objective problem is given by a Pareto set of solutions that indicates the existing trade-off between both objectives. The capabilities of the proposed framework are illustrated through two case studies, which solutions provide valuable insights into the design problem, and are intended to guide decision-makers towards the adoption of inherently safer process al ternatives. 


\section{INTRODUCTION}

For the past 30 years, the 100 largest incidents in the energy and chemical industries have risen to approximately $\$ 33$ billion losses ${ }^{1}$, and above all, they have cost fatalities, injuries and environmental damage. There is no doubt that process plants are dangerous places as they work with energy products and chemical transformations driven by energy; with hazardous substances or conditions; and with fuels that burn readily. Painful evidences of that fact are tragedies such as the Flixborough incident ${ }^{2}$ and the Bhopal gas disaster ${ }^{3}$. Therefore, as chemical engineers devoted to protecting the safety, heal th, and welfare of the public as well as protecting the environment for future generations, our commitment to developing safer process plants is inexorable. To reduce the frequency and consequences of accidents, process industries have developed hazard identification and analysis techniques (e.g., Failure, Modes and Effects Analysis, FMEA; Fault Tree Analysis, FTA; Event Tree Analysis, ETA; Cause-Consequence Analysis, CCA; Preliminary Hazard Analysis; Human Reliability Analysis, HRA; or Hazard and Operability Study, HAZOP). The most common method to mitigate risk and its consequences is by adding layers of protection with safety devices, which are included on later phases of the process design. Despite these protective measures have been successfully applied, they increase the complexity of the process and do not eliminate the hazards, which remain within the process and hence can provoke an unanticipated potential incident.

Alternatively to the addition of layers of protection, another design philosophy of hazard and risk management is based on the concept so-called inherently safer design (ISD), first expounded by Kletz ${ }^{4}$. The key idea of this philosophy was collected by Trevor Kletz in one phrase “ What you don't have, can't leak". Kletz suggested that the most effective approach 
to process risk management would be to focus on elimination or significantly reducing hazards where feasible, rather than managing them with safety systems and procedures. His insights led to what are now the four basic strategies to inherently safer design ${ }^{5}$ : minimize (or reduce inventories of hazardous materials); substitute (or replace hazardous substances, equipment or operations with less hazardous ones); moderate (or reduce hazards by dilution, refrigeration, or process alternatives that operate at less-hazardous conditions); and simplify (or eliminate unnecessary complexity). These principles are widely accepted, leading to a need for inherent safety in the current chemical industry ${ }^{6}$.

The best opportunity to incorporate inherently safer design principles lies in the early stages of the process design (conceptual design), where the degree of freedom for modification is still high. Conceptual design is the key step of a safe process, since the next steps are based on that one. A process conceived inherently safe reduces the final risk protection measures and therefore, the expenditures in safety equipment. Particularly, in the flowsheet design stage, all the interesting flowsheet alternatives can be combined into a superstructure, which later can be optimized ${ }^{7,8}$. This inherently safer design based on a superstructure demands to make decisions not only related to continuous process variables (temperatures, pressures, flowrates, compositions, etc.) but also to the process topology, which, in turn, implies the inclusion of integer variables in the model. Handling discrete decisions leads to a Mixed-Integer Nonlinear Programming (MINLP) problem ${ }^{9,10}$.

In addition, as stated by Mannan et. al. ${ }^{11}$, the incorporation of process simulators can provide further advancement in designing inherently safer plants. Flowsheeting software provides realistic simulations, and hence an optimal solution closer to the real implementation, thanks to the usage of tailored numerical techniques for each unit operation 
and an extensive component database along with reliable physical property methods. These advantages have been already highlighted by Shariff ${ }^{12}$, who illustrates the suitability of integrating the process simulator Aspen Hysys with a risk estimation tool. Despite modular process simulators are perfectly suited for simulation problems, they lose part of their attractiveness for optimization problems where the flowsheet topology is not kept fixed. This drawback arises from the rigid input-output structure of a modular process simulator that hinders the calculation of accurate derivatives, on which an efficient deterministic optimization algorithm relies ${ }^{13}$. As derivative information is not available in a modular process simulator, we must use a finite difference scheme by perturbing the independent variables. However, this calculation introduces truncation error and convergence noise into the optimization algorithm ${ }^{14}$. To take advantage of modular process simulators even for the case of structural flowsheet optimization, Navarro-Amorós ${ }^{15}$ developed a methodology that integrates modular process simulators under the Generalized Disjunctive Programming (GDP) framework. GDP offers an alternative representation of mixed-integer programming problems making the formulation step more intuitive and systematic, and retaining in the model the underlying logical structure of the problem. The development of GDP in the process system engineering (PSE) community has led to customized algorithms that exploit this alternative modelling framework. In particular, Turkay and Grossmann ${ }^{16}$ extended the outer approximation (OA) algorithm for MINLPs into a logical-equivalent algorithm.

A fact which deserves mention here is that optimization in PSE presents a lack of safety concerns (e.g., the objective function is not driven by safety indicators). An exception is the work of Suardin ${ }^{17}$, who draws our attention to incorporate safety aspects in the process optimization by adding safety constraints in the formulation of the problem for the design of 
reactor and distillation column systems. Therefore, there is a need to systematize the incorporation of inherent-safety principles by the deployment of powerful PSE methodologies ${ }^{18}$.

This paper aims to integrate inherently safer principles within the PSE framework to provide design solutions that are driven not only by the economic performance but also by the inherently safer indicator of the process. Accordingly, we formulate the synthesis of a chemical process as a bi-objective problem that seeks simultaneously to minimize the cost and the inherently safer indicators. We would like to emphasize that this work focuses on the early stages of the process design (i.e., conceptual design), where if the decisions are also driven by an inherently safer criterion, then the protective and control devices would be either eliminated or reduced its size in subsequent design stages. We assess the inherent safety of each design alternative extracted from the flowsheet superstructure by the Dow's Fire and Explosion index ${ }^{19}$, which has been previously used by other authors ${ }^{17,20}$ as an inherent safety metric. Two case studies illustrate our methodology: the chlorination of benzene, formulated as GDP and solved with a modelling language tool (GAMS); and the methanol production case study, where we use a modelling framework (in the Matlab environment) that interacts with the process simulator Aspen Hysys and commercial optimization solvers (TOMLAB).

The remainder of this article is organized as follows. The general problem is first formally stated and then the methodology is introduced. The logic based outer approximation algorithm, the integration of the process simulator in the algorithm and the connection with the external optimization solver are described at this point. The proposed simulation- 
optimization framework and its performance are illustrated through two case studies. In this section, the results are also described. Finally, we draw the conclusions from this work.

\section{METHODOLOGY}

The modelling framework proposed does not require reformulating the problem as an MINLP, allowing direct application of solution methods for GDP problems. To this aim, we use a homemade implementation of the logic based OA algorithm, explained below, with the special feature that also allows the use of implicit models (i.e., those models inside process simulators).

\subsection{Gener alized Disjunctive programing (GDP)}

As stated earlier, the GDP framework has been used. The general structure of a nonconvex GDP formulation is as follows:

$$
\begin{aligned}
& \min _{x, Y_{i k}, c_{k}} Z=\sum_{k \in K} C_{k}+f(x) \\
& \text { s.t. } h(x)=0 \\
& g(x) \leq 0 \\
& \quad\left[\begin{array}{c}
Y_{i k} \\
r_{i k}(x) \leq 0 \\
\left.\qquad \begin{array}{l}
\vee \\
s_{i k}(x)=0 \\
c_{k}=\gamma_{i k}
\end{array}\right], \quad k \in K
\end{array}\right. \\
& \Omega(Y)=\text { True } \\
& x^{\text {lo }} \leq x \leq x^{\text {up }}, x \in \mathbb{R}^{n}, c_{k} \in \mathbb{R}^{1} \\
& Y_{i k} \in\{\text { True, False }\}, i \in D_{k}, k \in K
\end{aligned}
$$

where $x$ is a vector of continuous variables representing pressures, temperatures and flowrates of the streams in a process superstructure. The objective function is a cost function, which has a variable term $(f(x))$ as a function of the continuous variables, $x$, and a constant 
term for the fixed cost of process task $k, c_{k}$. The common equality set of constraints, $h(x)=0$ , are the equipment performance equations and mass and energy balances; and the common set of inequalities, $g(x) \leq 0$, are the design specifications. Both sets of constraints must be applied regardless of the discrete decisions. The underlying alternatives in the superstructure are represented in the continuous space by a set of disjunctions $k \in K$, each of which contains $i \in D_{k}$ terms. Each term of the disjunction, denoted by a Boolean variable $Y_{i k}$, represents the potential existence of equipment (or stream) $i$ for performing the process task $k$, which is modelled by two sets of constraints $r_{i k}(x) \leq 0$ and $s_{i k}(x)=0$ (both form the disjunctive constraints), and the corresponding fixed cost $\gamma_{i k}$. When a term is not active $\left(Y_{i k}=\right.$ False $)$, the corresponding constraints are ignored. Finally, the logic equation $\Omega(Y)=$ True represents the set of logic propositions that relate the Boolean variables, which in PSE generally indicate equipment connections defining a feasible flowsheet.

\subsection{Solution method for the GDP}

A discrete decision problem formulated as a GDP can be tackle with two approaches: direct reformulation into an MINLP or usage of a logic based solution method. To fully exploit the logic structure underlying the GDP representation of the problem, we use the second approach, in particular, the Logic-based Outer Approximation (OA) algorithm ${ }^{16}$. The Logicbased OA shares the main idea of the traditional OA for MINLP (Mixed Integer NonLinear Programming), which is to solve iteratively a MILP master problem, which gives a lower bound of the solution $\left(z^{L B}\right)$, and a NLP subproblem, which provides an upper bound $\left(z^{U B}\right)$. The NLP subproblem is derived from the GDP representation of the problem by fixing the 
values of the Boolean variables $Y_{i k}$ (i.e, given a flowsheet configuration). The key difference of the logic approach versus the OA is that in the logic based OA algorithm only the constraints that belong to the selected equipment or stream (i.e., its associate Boolean variable $Y_{i k}^{l}=$ True $)$ are imposed. This leads to a substantial reduction in the size of the NLP subproblem compared to the direct application of the traditional OA method over the MINLP reformulation of the GDP problem. From the initial GDP representation of the problem, we build the linear GDP master problem that contains the linearizations of: the objective function, common constraints and disjunctive constraints inside the terms whose corresponding Boolean variable $Y_{i k}$ is True - linearizations of temporally inactive terms ( $Y_{i k}$ is False) are simply discarded (note that this property constitutes again a major difference to the standard OA method).

\subsection{GDP with an embedded simulator}

When rigorous thermodynamic models are needed, as in the second case study of thiswork, the use of a process simulator to access them is the preferred option. As we are dealing with a process simulator embedded in a GDP formulation, it is convenient to define a partition of the vector $x$ into dependent $x^{D}$ and independent (or design) variables $x^{I}$. The latter is the set of optimization variablesand its dimension is equal to the degrees of freedom of the nonlinear problem (i.e, when the set of binary variables are fixed). By this partition, the common equality constraint $h(\cdot)$ can be solved for a given vector of independent variables $x^{I}$, and then the dependent variables $x^{D}$ are expressed as functions of decision variables $x^{D}=h^{\text {Implicit }}\left(x^{I}\right)$. In an analogous manner, for each equipment $i$ assigned to a task $k$, the dependent variables 
associated to it can be expressed as functions of the decision variables $x^{D}=r_{i k}^{I m p l i c i t}\left(x^{I}\right)$. In this work, dependent variables $x^{D}$ are not explicitly written in terms of decision variables, but they are implicitly calculated within the process simulator and then, used at the optimization level to evaluate the objective function and the common and disjunctive constraints. Accordingly, the GDP problem (1) can be rewritten as:

$$
\begin{array}{ll}
\min _{x^{D}, x^{I}, Y_{i k}} & Z=f\left(x^{D}, x^{I}\right) \\
\text { s.t. } \quad & x^{D}=h^{\text {Implicit }}\left(x^{I}\right) \\
& h\left(x^{D}, x^{I}\right)=0 \\
& g\left(x^{D}, x^{I}\right) \leq 0 \\
& {\left[\begin{array}{l}
Y_{i k} \\
x^{D}=r_{i k}^{\text {Implicit }}\left(x^{I}\right) \\
\vee
\end{array}\right.} \\
& {\left[\begin{array}{l}
r_{i k}\left(x^{D}, x^{I}\right) \leq 0 \\
S_{i k}\left(x^{D}, x^{I}\right)=0
\end{array}\right] \quad k \in K} \\
& \Omega(Y)=\text { True } \\
& x^{I, l o} \leq x^{I} \leq x^{I, \text { up }} \\
& x^{D} \in \mathbb{R}^{n_{D}}, x^{I} \in \mathbb{R}^{n_{I}}, Y_{i k} \in\{\text { True, False }\}, i \in D_{k}, k \in K
\end{array}
$$

Note that in (2), as we introduce dependent variables in explicit equations (for example in $h\left(x^{D}, x^{I}\right)=0$ or in $\left.g\left(x^{D}, x^{I}\right) \leq 0\right)$, a sequential function evaluation is required. First, the implicit constraints are solved within the process simulator, and then, the explicit constraints are evaluated.

\subsection{Connection between Matlab and Aspen Hysys}

We use the binary-interface standard Component Object Model (COM), by Microsoft, to interact with Aspen HYSYS through the objects exposed by the developers of Aspen HYSYS. We utilize Matlab as an automation client to access these objects and interact with Aspen HYSYS, which works as an automation server. By writing Matlab code, it is possible to send and receive information to and from the process simulator (Figure 1). Thus, the exposed objects make it possible to perform nearly any action that is accomplished through 
the Aspen HYSYS graphical user interface, allowing us to use Aspen HYSYS as a calculation engine. In addition, we use the TOMLAB optimization environment as an interface between the model and the available optimization solvers. This tool allows us to standardize the model definition and then, use all the available solvers regardless of the different syntax required for each one. We use the CPLEX solver for the MILP problems and for the NLP supbroblems, the CONOPT solver.

\subsection{Dow's F\&E index as an inher ently safer index}

We assess the inherent safety of each design alternative extracted from the flowsheet superstructure by the Dow Fire and Explosion index ${ }^{19}$, which has been previously suggested as an inherent safety index by Kletz ${ }^{21}$ and also used by other authors ${ }^{17,} 20$ as a safety metric. The F\&El system is a step-by-step objective evaluation of the realistic fire, explosion and reactivity potential of process equipment and its contents. These steps can be followed through the Fire \& Explosion Index Hazard Classification Guide ${ }^{19}$, where the quantitative measurements used are based on historical loss data, the energy potential under study, and the extent to which loss prevention practices are currently applied. The method takes into account the items shown in Table 1, and applies a penal ty to each one depending on their contribution to the hazardousness of the process.

The Dow's F\&El value is computed from the Process Unit Hazard Factor, F3, and the material factor, MF, according to the following expression:

$$
\mathrm{F} \& \mathrm{EI}=M F \times F_{3}
$$


MF measures the intrinsic rate of potential energy released from a fire or explosion produced by the combustion or chemical reaction of the compounds involved. F3 contains all the factors that are likely to contribute to the occurrence of fire and explosion incidents. The value of $\mathrm{F}_{3}$ is computed by the multiplication of the general process hazard factor, $\mathrm{F}_{1}$, times the special process hazards factor, F2. General process hazard items play an important role in determining the magnitude of a loss incident, while special process hazards comprise the specific conditions that historically contribute to the major causes of fire and explosion incidents. Both factors, $\mathrm{F}_{1}$ and $\mathrm{F}_{2}$, are calculated in the same way, as the sum of a base factor, which is equal to 1, and the penalty factors applied for each hazard item. Then, expression (3) can be expanded as:

$$
\mathrm{F} \& \mathrm{EI}=M F \times \overbrace{\left(1+\sum_{i=1}^{6} \text { penalty }_{1, i}\right)}^{F_{1}} \times \overbrace{\left(1+\sum_{i=1}^{12} \text { penalty }_{2, i}\right)}^{F_{2}}
$$

where subscripts 1 and 2 refer to a general and special process hazard item, respectively

\subsection{Multi-objective optimization}

When a multi-objective optimization problem is solved, we usually do not find a solution which optimizes all the objectives (i.e. the utopia point). Instead, we obtain a set of solutions (i.e., the Pareto frontier) that shows the trade-off among the different objectives. Multiobjective optimization has been proved to be well suited to incorporate other objectives, different from the economic one, (such as environmental concerns) in the design of PSE systems ${ }^{22-24}$. 
In this work, we consider the two objective functions, the total annualized cost (TAC) and the inherently safer index accounted for by means of the Dow’s F\&EI. For the calculation of the Pareto frontier, we use the epsilon-constraint method ${ }^{25}$, which entails solving a set of instances of the following single-objective problem (5) for each value of the auxiliary parameter $\varepsilon_{p}$ that corresponds to each Pareto point $p$ :

$$
\begin{aligned}
& \min _{x, y} T A C \\
& \text { s.t. } \text { constraints } \\
& \\
& F \& E I \leq \varepsilon_{p} \\
& \underline{\varepsilon} \leq \varepsilon_{p} \leq \bar{\varepsilon}
\end{aligned}
$$

where the lower $(\underline{\varepsilon})$ and upper $(\bar{\varepsilon})$ limits, within which the epsilon parameter must fall, are obtained from the optimization of each objective separately (problems (6) and (7)):

$$
\begin{gathered}
(\tilde{x}, \tilde{y})=\arg \min _{x, y}\{\mathrm{TAC}\} \\
\text { s.t. constraints }
\end{gathered}
$$

which defines $\bar{\varepsilon}:=F \& E I(\tilde{x}, \tilde{y})$ and:

$$
\begin{gathered}
\underline{F \& E I}=\min _{x, y}\{F \& E I\} \\
\text { s.t. } \quad \text { constraints }
\end{gathered}
$$

which defines $\underline{\varepsilon}:=\underline{F \& E I}$.

The epsilon-constraint method algorithm implemented in GAMS is shown in Figure 2.

\section{CASE STUDIES}

\subsection{Case study I (chlorination of benzene)}

The first case study presented is that of the successive chl orination of benzene (expressed here as Bz). Two reactions were considered for the continuous chl orination of benzene where 
the desired product is monochlorobenzene $(\mathrm{ClBz})$ and dichlorobenzene $\left(\mathrm{Cl}_{2} \mathrm{Bz}\right)$ is the undesired product:

$$
\begin{aligned}
& \mathrm{Bz}+\mathrm{Cl}_{2} \stackrel{r_{1}}{\rightarrow} \mathrm{ClBz}+\mathrm{HCl} \\
& \mathrm{ClBz}+\mathrm{Cl}_{2} \stackrel{r_{2}}{\rightarrow} \mathrm{Cl}_{2} \mathrm{Bz}+\mathrm{HCl}
\end{aligned}
$$

The information relative to that reactive process was taken from ${ }^{26}$ : reactor type, CSTR; temperature, $55^{\circ} \mathrm{C}$; pressure, $1 \mathrm{~atm}$; and the following kinetic rate laws:

$$
\begin{aligned}
& r_{1}=k_{1} C_{B z} \\
& r_{2}=k_{2} C_{C \mid B z}
\end{aligned}
$$

where the rate constants at the above mentioned temperature are $\mathrm{k}_{1}=1.14 \times 10^{-4} \mathrm{~s}^{-1}$ and $\mathrm{k}_{2}$ $=1.53 \times 10^{-5} \mathrm{~s}^{-1}$.

After the reaction section, a separation sequence must be added in order to obtain the purified desired product $(\mathrm{ClBz})$ and the unreacted reactant $(\mathrm{Bz})$ to be recirculated to the reactor.

This first case study can be described by a relatively simple thermodynamic model, and hence, its mathematical formulation can be done without the need of a process simulator. Therefore, all the equations of the model were directly written in the modeling language GAMS. As stated before, the objective functions here are the total annualized cost (TAC) and the Dow's F\&EI index. A GDP formulation was used to accomplish the optimization of the system to obtain $\mathrm{ClBz}$ at the smallest cost and in the inherently safest possible way. We propose a superstructure that embeds all interesting flowsheet alternatives. Some of them are shown in Figure 3, where fresh benzene (Feed) is provided to the system and then mixed with a recycle $\mathrm{Bz}$ stream (Rec). This mixed stream feeds the reactor (Fin) together with chlorine that bubbles into it. The reactor product stream (Fout) enters a gas separator, where 
chlorhydric acid and chlorine are removed from the system. Then, the benzene, chlorobenzene and dichlorobenzene, contained in the liquid stream (Fsep), are separated by one of the considered al ternatives: direct and indirect separation (shown in Figure 3), with or without a thermally coupled distillation sequence, the use of a prefractionation column or a divided wall column. According to this superstructure, the flowsheet topology relies only on the optimal separation sequence. The GDP framework models these structural decisions by a set of disjunctions, which are, for this case study, only related to the existence or not of a given separation task. We have moved the complete model to Appendix SA of the Supporting Information to aim for brevity. Due to the non-linear nature of the problem, an initialization procedure has been performed for all the variables, that consists of the average value from the lower and upper bounds previously defined. In addition, for the Underwood roots, it is essential to provide tight upper and lower limits, which correspond to the volatilities of the adjacent components (sorted in decreasing volatilities val ues).

As mentioned before, one of the two objectives is the TAC, which is evaluated as shown in Eq. (9):

$$
\mathrm{TAC}=\frac{i r(1+i r)^{n}}{(1+i r)^{n}-1}[\text { Capital costs }]+\text { Operating costs }
$$

where $n$ stands for the total plant horizon time and ir is the fixed interest rate. In this case, we have used 10 years and $5 \%$ for these parameters.

One of the key decision variables for this bi-objective optimization problem is the volume of the reactor, since this value affects both, the economic and the inherently safer objective functions. Determining the optimal reactor volume together with the most appropriate separation sequence is the main target of this case study. Since the two in series reactions under consideration are irreversible, the bigger the reactor volume, the smaller the flowrate 
of the reactant Bz left for the recirculation stream (higher conversion as a consequence of the higher residence time), but simultaneously, the higher the flowrate of the undesired $\mathrm{Cl}_{2} \mathrm{Bz}$ that appears in the outlet stream from the reactor (i.e., poorer selectivity towards the desired product, $\mathrm{ClBz}$ ). Regarding cost assessment, as reactor volume increases, the TAC of the reactor also increases (see Figure 6). However, the reactor volume also affects the TAC of the separation section in the opposite sense, since a small reactor volume leads to a $\mathrm{Bz}$ recirculation stream with a higher flowrate, which, in turn, implies larger operating costs (i.e., higher TAC) for the separation tasks (Figure 6).

As the reactor volume provides a measure of the energy of the system, by controlling this decision variable, we can apply one of the principles of ISD, which is minimization. Particularly, the value of item $G$ in the Special Process Hazards Factor $\left(F_{2}\right)$ of the F\&EI accounts for the total amount of flammable/unstable materials that might be spilled and create a fire hazard. We remark that the remainder items of F\&EI, in both factors $F_{1}$ and $F_{2}$, are independent of the decision variables of the problem, and hence they remain constant during the optimization process (see Table 1). To compute item G, we need the total energy of the system (we maintain the original units of the Dow's F\&EI guide, TOTAL BTU ), which can be calculated from two alternative bases. On one hand, from the amount of the flammable/unstable materials inside the process unit (i.e., the reactor volume):

$$
\text { TOTAL BTU }_{\text {Volume }}=V \sum_{j} M_{j} h_{j}^{\text {combustion }} C_{j}
$$

where $V$ is the volume of the reactor, $M_{j}$ is the molar mass of component $j, h_{j}^{\text {combustion }}$ is the heat of combustion for component $j$ and $C_{j}$ is the concentration of component $j$ in the reactor. On the other hand, the basis can also be the amount of flammable/unstable material that can be released from the stream with the highest mass flowrate in the whole flowsheet 
(for this case study the outlet stream to the reactor) during a specific amount of time $t$ (i.e. 10 minutes):

$$
\text { TOTAL BTU } \text { flowrate }=t \sum_{j} M_{j} h_{j}^{\text {combustion }} m_{j}
$$

where $m_{j}$ is the mass flowrate of component $j$. From the maximum of these two values of the total energy computed by Eq. (10) and Eq. (11), a penalty for the G item is obtained using the correlation (namely $f_{G}^{\text {PENALTY }}$ ) given in the F\&EI guide ${ }^{19}$ :

$$
\text { G item in } F_{2}=f_{G}^{\text {PENALTY }}\left(\max \left(\mathrm{TOTAL} \mathrm{BTU}_{\text {volume }}, \text { TOTAL BTU } \mathrm{flowrate}\right) \times 10^{-9}\right)
$$

In addition, as the max operator introduces a discontinuity in the model, we compute item G by replacing Eqs. (10)-(12) for the following set of constraints, which are perfectly suited for an optimization problem:

$$
\begin{aligned}
& \text { TOTAL BTU } \geq V \sum_{j} M_{j} h_{j}^{\text {combustion }} C_{j} \\
& \text { TOTAL BTU } \geq t \sum_{j} M_{j} h_{j}^{\text {combustion }} m_{j} \\
& \text { Gitem in } F_{2}=f_{G}^{\text {PENALTY }}\left(\text { TOTAL BTU } \times 10^{-9}\right)
\end{aligned}
$$

We further remark that the energy ( TOTAL BTU) contained in the separation system is lower than the one confined in the reactor. Indeed, the configuration of the separation system that encloses the highest amount of energy only reaches the $50 \%$ of the corresponding value inside the reactor even at the lowest reactor volume considered $\left(12 \mathrm{~m}^{3}\right)$.

By implementing the epsilon constrain method (described in section 2.6) in GAMS (model statistics shown in Table 2), we obtain the Pareto set of solutions (Figure 4). As seen in this figure, there is a clear trade-off between the economic indicator and the F\&El, since reductions in TAC can only be achieved by compromising the inherently safer index. Note that each point of the Pareto set entails a specific topology for the separation section and a set of values for all the variables of the problem. In particular, Figure 5 shows the 
configuration of the separation section for the two extreme solutions: the minimum F\&EI and the minimum TAC.

Furthermore, Table 3 shows the optimal values for some variables at the extreme Pareto solutions, where Qreactor is the heat flow removed from the reactor and Qreboiler and Qcondenser are the energy flows at the reboiler and condenser of the distillation sequence, respectively. A deeper insight into the cost distribution discloses that the separation costs are higher than those attributed to the reactor within the range of reactor volume considered (Figure 6).

\subsection{Case study II (methanol production)}

We extend the proposed methodology to a case study that presents different flowsheet al ternatives for the synthesis of methanol, which has been studied extensively in the past ${ }^{27-}$ ${ }^{29}$. Particularly, we focus in one of the three main sections of a methanol plant, the reaction section, where the synthesis gas reacts to produce methanol following this reaction system:

$$
\begin{array}{lrl}
\mathrm{CO}+2 \mathrm{H}_{2} \rightarrow \mathrm{CH}_{3} \mathrm{OH} & \Delta H_{r \times n}^{\circ}=-94.5 \mathrm{~kJ} / \mathrm{mol} \\
\mathrm{CO}_{2}+3 \mathrm{H}_{2} \rightarrow \mathrm{CH}_{3} \mathrm{OH}+\mathrm{H}_{2} \mathrm{O} & \Delta H_{r \times n}^{\circ}=-53 \mathrm{~kJ} / \mathrm{mol} \\
\mathrm{CO}+\mathrm{H}_{2} \mathrm{O} \leftrightarrow \mathrm{CO}_{2}+\mathrm{H}_{2} & \Delta H_{r \times n}^{\circ}=-41.21 \mathrm{~kJ} / \mathrm{mol}
\end{array}
$$

These reactions are not independent, and then, only two of them are required for a complete description of the reaction system (see Appendix SB in the Supporting Information for the rate laws and the corresponding kinetic parameters), which exhibits a trade-off between the conversion reached according to the thermodynamic equilibrium and the time to reach that equilibrium governed by reaction kinetics —equilibrium predicts higher conversions at lower temperatures (Figure 7a), but kinetics leads to lower reaction rates at those temperatures 
(Figure 7b), which, in turn, decrease the conversion at the outlet stream of a given reactor under a specific pressure- - Figure 7c highlights that conversions predicted by equilibrium are higher than conversions derived from kinetics at any combination of temperature and pressure. Thus, the behavior of this reaction system demands to seek for the intermediate temperature (i.e., optimal temperature) that provides the maximum $\mathrm{CO}$ conversion for a given pressure in a particular reactor.

Conventional methanol production uses a feed stock of reformed methane that contains hydrogen, carbon monoxide and carbon dioxide characterized by the parameter $M=\left(\mathrm{H}_{2}-\mathrm{CO}_{2}\right) /\left(\mathrm{CO}+\mathrm{CO}_{2}\right)$ (often referred as the $\mathrm{M}$ module) and the ratio of $\mathrm{H}_{2}$ to $\mathrm{CO}$. The value of the former parameters affects also the conversion of the reactor.

Figure 8 shows the superstructure that contains the flowsheet alternatives for the methanol reaction section of the plant. The topology alternatives arise from the two types of the feed stream, the compression systems — located at the feed and recycle stream — that have one or two compressors and can operate at low and high pressure, and the two reaction subflowsheets for the low and high operating pressure. As a result, the superstructure contains 64 alternative flowsheet topologies, which are modelled under the generalized disjunctive programming framework using 12 Boolean variables.

As said before, two of the alternatives embedded in the proposed superstructure arise from the type of feed to the system, where two streams with different values of the M parameter and $H_{2}$ to $\mathrm{CO}$ ratio can be selected (Table 4). We calculate the cost of each stream as a weighted mean of the $\mathrm{H}_{2}$ (75 \$/tonne) and $\mathrm{CO}_{2}$ (53.6 \$/tonne) prices ${ }^{30}$, where the weights are the mass fractions of $\mathrm{H}_{2}$ and $\mathrm{CO}_{2}$. 
For the gas compression block (both, at the feed and at the recycle stream), one or two compressors (with intermediate cooling) can be used. In addition, for each compression alternative, two levels for the output pressure (low, 50 atm, and high, 150 atm) can be chosen. As an example, Figure 9 shows the two terms OR exclusive disjunction that models the structural options available in the feed compression block at the highest level of pressure. The small flowsheet included in each term symbolizes the equations solved by the process simulator (i.e., implicit constraints) once the values of the independent variables (i.e., $T^{\text {inter }}$ and $P^{\text {inter }}$ ) are provided by the optimizer. Note that each term only includes the constraints that are forced to be included in the model if the corresponding Boolean variable is true —if one stage compressor is selected then it does not make sense to evaluate the cost of a nonexisting intermediate cooler- For the low pressure level, a similar disjunction is added in the GDP model to the potential use of one or two stages compression system.

Regarding the reaction block, we consider two alternative subflowheets (shown in the two terms of the disjunction of Figure 10) operating under different pressures, at low, 50 atm and at high, $150 \mathrm{~atm}$. To adjust the gas mixture temperature to the inlet conditions of the reactor, the high pressure reaction subflowsheet requires a heater, whereas the low pressure alternative contains a cooler. Modelling this discrete decision by the GDP framework enables us to set different lower and upper bounds for the independent variables (inlet temperature, $T^{\text {in,low }}, T^{\text {in,high }}$; reactor length, $L^{\text {low }}, L^{\text {high }}$; outlet pressure $P^{\text {low }}, P^{\text {high }}$; and temperature, $\left.T^{\text {low }}, T^{\text {high }}\right)$, depending on whether they belong to the low or high pressure alternative. Note also that we pose the same type of reactor, a Plug Flow Reactor (PFR), for both alternatives, but the flexibility of the GDP formulation permits the use of different reactors in each alternative if necessary. 
The alternative flowsheet configurations affect the inherently safer design ISD index. For example, the ISD moderate principle is reflected in the choice between the reactor block at high or low pressure. In view of that, we quantify the safety level of both options by the DOW's Fire \& Explosion index with its Special Process Hazards factor $\left(\mathrm{F}_{2}\right)$ in the item E, Pressure; penalties are assigned to the operating and relief pressures to calculate item $\mathrm{E}$ as follows:

$$
\text { item } E \text { in } F_{2}=1.2 \frac{\left.P E N A L T Y^{2} \text { (operating pressure }\right)}{\text { PENALTY }(\text { relief pressure })}
$$

where the penalty values are computed using the correlation given in the F\&EI guide ${ }^{19}$. The original correlation that computes this penalty in the F\&EI is valid for an upper limit of 1000 psig (69 bar), and for higher pressures, the penalty values are determined by the table 4 of the F\&EI guide ${ }^{19}$. As we want to formulate an optimization problem, a smooth penalty function — whose domain also includes pressure values higher than 1000 psig — is required. Therefore, we fit the data of the table 4 of the F\&EI to a cubic smoothing spline. Figure 11 reproduces this fit and highlights the two pressure levels of the superstructure.

The flowsheet alternatives proposed contemplate another principle of ISD, which is minimization. The total amount of flammable/unstable materials that might be spilled and create a fire hazard (item $\mathrm{G}$ in factor $\mathrm{F}_{2}$ of the F\&EI) is determined from the total energy of the system, which is computed from the heat of combustion of the hazard components in this case study: $\mathrm{H}_{2}$, $\mathrm{CO}$ and $\mathrm{CH}_{3} \mathrm{OH}$. From the maximum value of the total energy ( TOTAL BTU ), a penalty for item $G$ is computed by eq (14). As alternative configurations use different sizes for the reactor (or different mass flowrates), these configurations exhibit different values for the ISD index. For this case study, items E and G vary with the decision variables 
and the remaining items of the F\&EI are constant. Table 1 column 4 shows the values of the items required to compute the F\&EI.

Using the epsilon constraint method (see section 2.6) and the logic based outer approximation algorithm, we solve the bi-objective problem that seeks for simultaneously minimize the TAC and the F\&EI (see Table 2 for model statistics). Regarding the initialization procedure, we follow the approach suggested by Türkay and Grossmann $(1996)^{16}$ based on solving a set-covering problem to determine the minimum number of NLP subproblems (i.e. feasible flowsheet alternatives), providing outer approximations for all the units. For this case study, four initial NLP subproblems are required to be solved.

In Figure 12, the points are the Pareto set of solutions, whereas the edge of the shadow region provides a subestimation of the Pareto frontier, which exhibits a clear trade-off between the economic and the inherent safety indicators, since reductions in the F\&EI can only be achieved by compromising the TAC of the methanol plant. In particular, regarding the extreme solutions - minimum F\&EI extreme solution (green point at the left extreme of the Pareto set of solutions, located at 127.0 points for the $\mathrm{F} \& \mathrm{El}$ and $95.6 \times 10^{5} € \cdot \mathrm{year}^{-1}$ ) and minimum TAC extreme solution (red point at the right extreme of the Pareto set of solutions, located at 135.2 points for the F\&El and $84.9 \times 10^{5} € \cdot$ year $\left.^{-1}\right)$ - , from the F\&El extreme solution to the TAC extreme solution, the F\&EI value increases $6.5 \%$ whereas the TAC decreases $12.6 \%$. Note that each Pareto point can entail a different flowsheet configuration with its corresponding optimal values for the decision variables. Figure 13 shows the flowsheet and main variablesfor both extreme solutions. At the minimum F\&El (Figure13a), the reactor operates at the lowest pressure (50 atm). On the contrary, for the minimum TAC extreme solution (Figure 13b), the higher pressure reactor is selected. In both extreme 
solutions, the single-stage compressor is selected for the two compression systems, the feed and the recycle. The two stage compressor is not selected because this configuration implies a lower outlet temperature of the gas mixture (compared with one-stage compressor) as it cotains an intercoller between stages. As we proved that significant conversion requieres reactor temperatures above $200^{\circ} \mathrm{C}$, then a high temperature of the gas mixture is required to avoid a excesive heat flux in the heat exchanger previous to the reactor. In both topologies, the optimal reactor length decision variable is active at ist upper bound, $12 \mathrm{~m}\left(98.9 \mathrm{~m}^{3}\right)$. The optimal temperature for the isothermal PFR in the mimimum F\&EI extreme solution is 246 ${ }^{\circ} \mathrm{C}$, that yields a $\mathrm{CO}$ conversion of $72.9 \%$ and a $\mathrm{CO}_{2}$ conversion of $43.3 \%$, whereas for the TAC extreme solution the reactor temperature is $214.1^{\circ} \mathrm{C}$ with a $\mathrm{CO}$ conversion of $96.1 \%$ and a $\mathrm{CO}_{2}$ conversion of $94.6 \%$.

As can observed in the TAC break down shown in Figure 14, the utility costs exceed the annualized capital costs, and the main contribution to the TAC is the raw materials consumption, for both extreme solutions. For the minimum F\&EI (a), the second main contribution to the TAC is the heater before the reactor $\left(27.9 \times 10^{5} € \cdot\right.$ year $\left.^{-1}\right)$, whereas for the minimum TAC (b), it arises from the compression systems (feed and recycle, $12.19 \times 10^{5}$ $€ \cdot$ year $^{-1}$ and $23.3 \times 10^{5} € \cdot$ year $^{-1}$, respectively). The difference of the heater cost is higher than that of the compression system cost between both extreme solutions. This fact leads to the lower TAC for the economical extreme solution. For the minimum F\&EI extreme solution, the expensiveness of the heater before the reactor is due to the high duty demand, as a consequence of the temperature $\left(246^{\circ} \mathrm{C}\right)$ required in the reactor to achieve a significant conversion working at such low pressure (50 atm). 
As explained before, the inherently safer index depends on the pressure and the total energy of the system. Figure 15 shows contour plots of the inherently safer objective as a function of the reactor operating pressure and the mass flowrate with the highest energy content (feed stream to the reactor). For each extreme solution, the F\&EI value is annotated with a circle (127 points in the min F\&EI and 135.2 points in the min TAC). In the y-axis of Figure 15a and Figure 15b, we use the mass flowrate (Eq. (11)) instead of the volume of the reactor (Eq. (10)) as a basis to compute the G item of the F\&EI, because the total energy content computed from the volume reactor is lower than that derived from the mass flowrate. Specifically, for the min F\&EI extreme solution, the G item calculated with the stream as basis is 0.77 points, whereas the value computed from the volume is 0.01 ; for the min TAC extreme solution, $G$ item from the stream is 0.73 points and the same item computed from the volume is 0.11 . In addition, we consider that the mass flowrate shown in Figure 15 results from the summation of the 3 components that contribute to the total energy content, $\mathrm{H}_{2}$, $\mathrm{CO}$ and $\mathrm{CH}_{3} \mathrm{OH}$ (i.e., those compounds with a heat of combustion greater than 0). Remark that the contour plots in Figure 15 are slightly different for each flowsheet configuration of the extreme solutions. The fact that the percentage factor to compute the relief pressure changes as the operating pressure does (recall that item E of the F\&EI depends on the pressure) originates the different contour maps. Hence, for the low pressure flowsheet (50 atm) this percentage is 20 \% (i.e., a relief pressure of $60 \mathrm{~atm}$ ) and for the high pressure alternative (150 atm), the percentage decreases to $5 \%$ (i.e., a relief pressure of 158 atm). The possibility of modelling this discrete change, which affects the equation to compute item E (Eq. (14) ), is another benefit from the GDP framework. 
The difference in the F\&EI value at the two extreme solutions is due to the relative contribution of the items E and G, which are the ones that depend on the decision variables, pressure and mass flowrate, respectively. To highlight the F\&EI dependence on these two decision variables Eq. (4) can be rewritten as follows:

$$
\begin{aligned}
& \text { F\&EI }=M F \times F_{1} \times\left(F_{2}^{\text {constant }}+\text { Item } E+\text { Item } G\right)= \\
& =\overbrace{M F \times F_{1} \times F_{2}^{\text {constant }}}^{\text {Constant contribution }}+\overbrace{M F \times F_{1} \times \text { Item } E}^{\text {E item contribution }}+\overbrace{M F \times F_{1} \times \text { Item } G}^{G \text { item contribution }}
\end{aligned}
$$

Note that the general process hazard factor, $\mathrm{F}_{1}$, takes the same value for all the Pareto solutions. The split of the F\&EI in the three contributions defined in Eq. (15) points out that the lower value of the inherently safer index attained by the min F\&EI extreme solution is caused by the decrease in the E item contribution (Figure 16). Despite the decrease of the contribution of item $\mathrm{G}$ in the min TAC extreme solution (lower mass flowrate entering the reactor), this reduction cannot compensate the increase in the contribution of item $\mathrm{E}$-in the min TAC extreme solution the reactor operates at the maximum pressure, $150 \mathrm{~atm}$.

\section{CONCLUSIONS}

The suitability of deploying well-established PSE tools for the conceptual design of inherently safer chemical processes has been confirmed by this work. In particular, we have taken advantage of the Generalized Disjunctive Programming (GDP) framework to address the problem of inherently safer design of chemical processes. The solution entailsthe optimal values for the continuous variables and the best flowsheet configuration (discrete decisions). The problem addressed here has been mathematically formulated as bi-criterion GDP problem that accounts for the minimization of both Total Annual Cost (TAC) and the Dow's 
Fire \& Explosion Index (F\&EI). Despite its simplicity, the F\&EI has been proven valid as an inherently safer index as it is able to quantify the minimization and moderation principles of inherent safety philosophy. The GDP methodology has been deployed through different tools in two case studies: the chlorination of benzene, and the methanol production. The solutions for both case studies provide valuable insights into the design problem and guide the decision-maker in the adoption of inherently safer alternatives in the first stage of process plant design. Regarding the sensitivity of Dow’s F\&EI to variations in the design variables, pressure and temperature, E item is directly related with the pressure whereas there is only an implicit relation with the temperature through the $G$ item -the modification in the temperature of the equipment or stream has an effect on other process variables and sizing parameters such the molar flowrate in the recycle stream, or the size of the reactor (for example, temperature modifies kinetic rates, which in turns determines the reactor volume). To achieve an explicit relation of the ISI as a function of the temperature, further work will involve the incorporation of a new inherently safer index composed of weighted contributions chosen from the set of available safety (including the Dow's F\&EI) and inherently safer indexes.

\section{Acknowledgements}

The authors acknowledge financial support from "Proyectos de $1+D$ para grupos de investigación emergentes GV/2016/005' (Conselleria d'Educació, Investigació, Cultura i Esport, GENERALITAT VALENCIANA) and from the Spanish "Ministerio de Economía, Industria y Competitividad" (CTQ2016-77968-C3-02-P, AEI/FEDER, UE). 


\section{Supporting information}

- Detailed GDP model of the production of monochlorobenzene (Appendix SA).

- Kinetic data adaptation to the Aspen Hysys Kinetic expression for the methanol reaction system (Appendix SB). 


\section{Liter atur e cited}

(1) Edwards, V. H., How to Make Process Plants Inherently Safer. PE Magazine2014.

(2) Kletz, T. A., Learning from accidents. 3rd ed.; Gulf Professional: Oxford; Boston, 2001; $p \times i, 345 p$.

(3) Gupta, J. P., The Bhopal gas tragedy: Could it have happened in a developed country? Journal of Loss Prevention in the Process Industries2002, 15, (1), 1-4.

(4) Kletz, T. A., INHERENTLY SAFER PLANTS. Plant/operations progress 1985, 4, (3), 164-167.

(5) Kletz, T. A.; Amyotte, P., Process plants a handbook for inherently safer design. 2nd ed.; CRC Press/Taylor \& Francis: Boca Raton, FL, 2010; p xxi, 362 p.

(6) Srinivasan, R.; Natarajan, S., Developments in inherent safety: A review of the progress during 2001-2011 and opportunities ahead. Process Safety and Environmental Protection 2012, 90, (5), 389-403.

(7) Kidam, K.; Sahak, H. A.; Hassim, M. H.; Shahlan, S. S.; Hurme, M., Inherently safer design review and their timing during chemical process development and design. Journal of Loss Prevention in the Process Industries2016, 42, 47-58.

(8) Ordouei, M. H.; Elkamel, A.; Al-Sharrah, G., New simple indices for risk assessment and hazards reduction at the conceptual design stage of a chemical process. Chemical Engineering Science 2014, 119, 218-229.

(9) Biegler, L. T.; Grossmann, I. E.; Westerberg, A. W., Systematic methods of chemical process design. Prentice Hall PTR: Upper Saddle River, N.J., 1997; p xviii, 796 p. 
(10) Grossmann, I. E., Review of Nonlinear Mixed-Integer and Disjunctive Programming Techniques. Optimization and Engineering 2002, 3, 227-252.

(11) Mannan, M. S.; Sachdeva, S.; Chen, H.; Reyes-Valdes, O.; Liu, Y.; Laboureur, D. M., Trends and challenges in process safety. A/ChE Journal 2015, 61, (11), 3558-3569.

(12) Mohd Shariff, A.; Rusli, R.; Leong, C. T.; Radhakrishnan, V. R.; Buang, A., Inherent safety tool for explosion consequences study. Journal of Loss Prevention in the Process Industries2006, 19, (5), 409-418.

(13) Caballero, J. A.; Navarro, M. A.; Ruiz-Femenia, R.; Grossmann, I. E., Integration of different modelsin the design of chemical processes: Application to the design of a power plant. Applied Energy2014, 124, 256-273.

(14) Wolbert, D.; Joulia, X.; Koehret, B.; Biegler, L. T., Flowsheet optimization and optimal sensitivity analysis using analytical derivatives. Computers and Chemical Engineering 1994, 18, (11-12), 1083-1095.

(15) Navarro-Amorós, M. A.; Ruiz-Femenia, R.; Caballero, J. A., Integration of modular process simulators under the Generalized Disjunctive Programming framework for the structural flowsheet optimization. Computers and Chemical Engineering 2014, 67, 13-25.

(16) Türkay, M.; Grossmann, I. E., Logic-based MINLP algorithms for the optimal synthesis of process networks. Computers and Chemical Engineering 1996, 20, (8), 959-978.

(17) Suardin, J.; Sam Mannan, M.; El-Halwagi, M., The integration of Dow's fire and explosion index (F\&EI) into process design and optimization to achieve inherently safer design. Journal of Loss Prevention in the Process Industries2007, 20, (1), 79-90. 
(18) Leveson, N. G.; Stephanopoulos, G., A system-theoretic, control-inspired view and approach to process safety. A/ChE Journal 2014, 60, (1), 2-14.

(19) Dow, Dow's fire \& explosion index hazard classification guide. 7th ed:; American Institute of Chemical Engineers: New York, 1994; p 83 p.

(20) Al-Mutairi, E. M.; Suardin, J. A.; Mannan, M. S.; El-Halwagi, M. M., An optimization approach to the integration of inherently safer design and process scheduling. Journal of Loss Prevention in the Process Industries2008, 21, (5), 543-549.

(21) Kletz, T. A., Process plants: a handbook for inherently safer design. Taylor \& Francis: Philadelphia, PA, 1998; p xiv, 209 p.

(22) Grossmann, I. E.; Guillén-Gosálbez, G., Scope for the application of mathematical programming techniques in the synthesis and planning of sustainable processes. Computers \& Chemical Engineering 2010, 34, (9), 1365-1376.

(23) Sal cedo, R.; Antipova, E.; Boer, D.; Jiménez, L.; Guillén-Gosál bez, G., Multi-objective optimization of solar Rankine cycles coupled with reverse osmosis desalination considering economic and life cycle environmental concerns. Desalination 2012, 286, 358-371.

(24) Ruiz-Femenia, R.; Guillén-Gosál bez, G.; Jiménez, L.; Caballero, J. A., Multi-objective optimization of environmentally conscious chemical supply chains under demand uncertainty. Chemical Engineering Science2013, 95, 1-11.

(25) Ehrgott, M., Multicriteria optimization. 2nd ed.; Springer: Berlin ; New York, 2005; p xiii, 323 p. 
(26) Fogler, H. S., Elements of chemical reaction engineering. 4th ed.; Prentice Hall PTR: Upper Saddle River, NJ, 2006; p xxxii, 1080 p.

(27) Luyben, W. L., Design and control of a methanol reactor/column process. Industrial and Engineering Chemistry Research 2010, 49, (13), 6150-6163.

(28) Bell, D. A.; Towler, B. F.; Fan, M.; Books24x7 Inc., Coal gasification and its applications. In 1st ed.; William Andrew,: Oxford, U.K. ; Burlington, Mass., 2011.

(29) Abrol, S.; Hilton, C. M., Modeling, simulation and advanced control of methanol production from variable synthesis gas feed. Computers and Chemical Engineering 2012, 40, $117-131$.

(30) Seungjune, C.; Jehun, P.; Chonghun, H.; En, S. Y., Optimal design of synthesis gas production process with recycled carbon dioxide utilization. Industrial and Engineering Chemistry Research2008, 47, (2), 323-331. 


\section{TABLES}

Table 1. Hazard items to cal cul ate the Dow's Fire and Explosion Index with the penal ty ranges

for the general case and for the two case studies.

\begin{tabular}{|c|c|c|c|c|}
\hline \multicolumn{2}{|l|}{ ITEM } & $\begin{array}{c}\text { Penalty Range } \\
\text { (general) }\end{array}$ & $\begin{array}{l}\text { Penalty Range } \\
\text { (case study 1) }\end{array}$ & $\begin{array}{l}\text { Penalty Range } \\
\text { (case study } 2 \text { ) }\end{array}$ \\
\hline \multicolumn{2}{|c|}{ Material Factor (MF) } & 1 to 40 & $16(\mathrm{Bz})$ & $21\left(\mathrm{H}_{2}\right)$ \\
\hline \multicolumn{5}{|c|}{ General Process Hazards Factor $\left(F_{1}\right)$} \\
\hline A. & Exothermic Chemical Reactions & 0.00 to 1.25 & 1.00 & 0.30 \\
\hline B. & Endothermic Processes & 0.00 to 0.40 & 0.00 & 0.00 \\
\hline C. & Material Handling and Transfer & 0.00 to 1.05 & 0.00 & 0.00 \\
\hline D. & Enclosed or Indoor Process Units & 0.00 to 0.90 & 0.00 & 0.00 \\
\hline E. & Access & 0.00 to 0.35 & 0.00 & 0.00 \\
\hline F. & Drainage and Spill Control & 0.00 to 0.50 & 0.00 & 0.00 \\
\hline \multicolumn{5}{|c|}{ Special Process Hazards Factor $\left(F_{2}\right)$} \\
\hline A. & Toxic Material(s) & 0.0 to 0.80 & 0.80 & 0.60 \\
\hline B. & Sub-Atmospheric Pressure (< 500 mm Hg) & 0.50 & 0.00 & 0.00 \\
\hline \multicolumn{5}{|c|}{ C. Operation In or Near Flammable Range } \\
\hline & 1. Tank Farms Storage Flammable Liquids & 0.50 & 0.50 & 0.50 \\
\hline & 2. Process Upset or Purge Failure & 0.30 & 0.00 & 0.00 \\
\hline & 3. Always in Flammable Range & 0.80 & 0.00 & 0.00 \\
\hline D. & Dust Explosion & 0.00 to 2.00 & 0.00 & 0.00 \\
\hline E. & Pressure & 0.00 to 1.2 & 0.17 & {$[0.9-1.15]$} \\
\hline F. & Low Temperature & 0.0 to 0.30 & 0 & 0 \\
\hline \multicolumn{5}{|c|}{ G. Quantity of Flammable/Unstable Material: } \\
\hline \multicolumn{2}{|r|}{ 1. Liquids or Gases in Process } & 0 to 3 & [0.83-1.29] & {$[0.19-0.90]$} \\
\hline \multicolumn{2}{|r|}{ 2. Liquids or Gases in Storage } & 0 to 1.8 & & \\
\hline \multicolumn{2}{|r|}{ 3. Combustible Solids in Storage, Dust in Process } & 0 to 10 & & \\
\hline & Corrosion and Erosion & 0.00 to 0.75 & 0.00 & 0.00 \\
\hline I. & Leakage - Joints and Packing & 0.00 to 1.50 & 0.00 & 0.00 \\
\hline J. & Use of Fired Equipment & 0.00 to 1.00 & 0.00 & 0.00 \\
\hline & Hot Oil Heat Exchange System & 0.00 to 1.15 & 0.00 & 0.00 \\
\hline L. & Rotating Equipment & 0.50 & 0.00 & 0.50 \\
\hline
\end{tabular}


Table 2. Model statistics

\begin{tabular}{lcc}
\hline & case study 1 & case study 2 \\
\hline Number of binary variables & 29 & 12 \\
\hline Number of variables & 255 & 94 \\
Dependent & - & 65 \\
Independent & - & 29 \\
\hline Number of linear explicit constraints & 402 & 73 \\
\hline Number of nonlinear explicit constraints & 94 & 62 \\
\hline
\end{tabular}


Table 3. Optimal values for the extreme solutions of the Pareto curve.

\begin{tabular}{lll}
\hline & Safety optimum & Economic optimum \\
\hline F\&EI & 105.7 & 120.4 \\
TAC (k€/year) & 2674.7 & 911.9 \\
Reactor volume $\left(\mathrm{m}^{3}\right)$ & 12 & 26 \\
Qreactor $(\mathrm{kW})$ & 1861.7 & 2112.1 \\
Distillation sequence & $\begin{array}{l}\text { Prefractionator with } \\
\text { thermocouple instead of }\end{array}$ & Divided Wall Column \\
& condenser (Figure 5a) & (Figure 5b) \\
Qreboiler $(\mathrm{kW})$ & $4044.3+1552.3$ (2 reboilers) & 1068.5 \\
Qcondenser $(\mathrm{kW})$ & 1906.1 & 831.1 \\
\hline
\end{tabular}


Table 4. Composition and price of the alternative feed streams embedded in the superstructure.

\begin{tabular}{|c|c|c|c|c|c|c|}
\hline \multirow{2}{*}{ Feed type } & \multirow{2}{*}{ Cost $(€ / \mathrm{kg})$} & \multicolumn{3}{|c|}{ Composition (mole fractions) } & \multirow{2}{*}{$M=\frac{H_{2}-C O_{2}}{C O+C O_{2}}$} & \multirow{2}{*}{$\frac{H_{2}}{C O}$} \\
\hline & & $\mathrm{H}_{2}$ & $\mathrm{CO}$ & $\mathrm{CO}_{2}$ & & \\
\hline Feed A & 0.041 & 0.71 & 0.27 & 0.02 & 2.4 & 2.7 \\
\hline Feed B & 0.042 & 0.77 & 0.18 & 0.05 & 3.1 & 4.3 \\
\hline
\end{tabular}




\section{Figures}

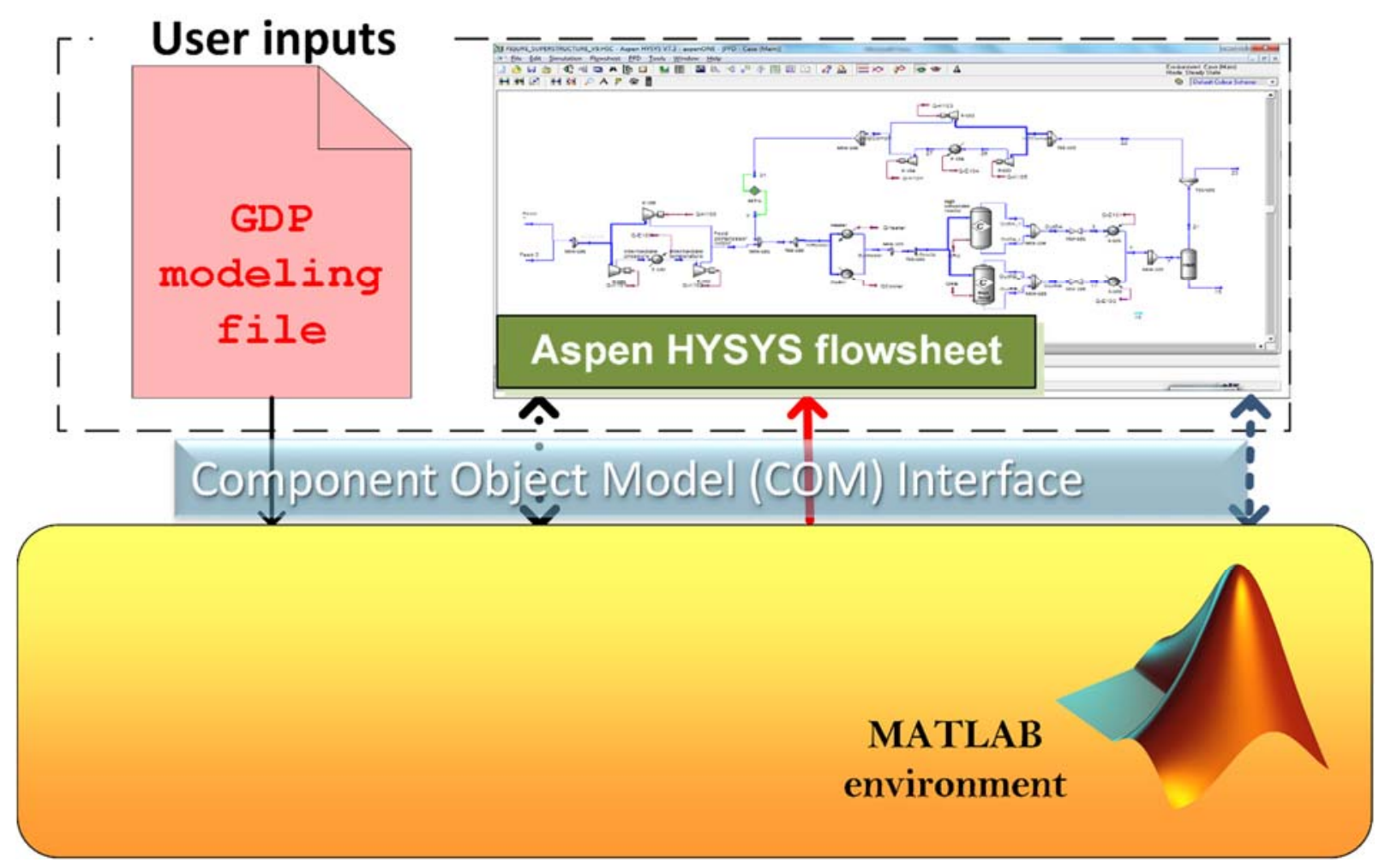

Figure 1. Scheme of the connection between the Matlab environment and the user inputs: the GDP modelling file and the superstructure flowsheet built in the process simulator. 


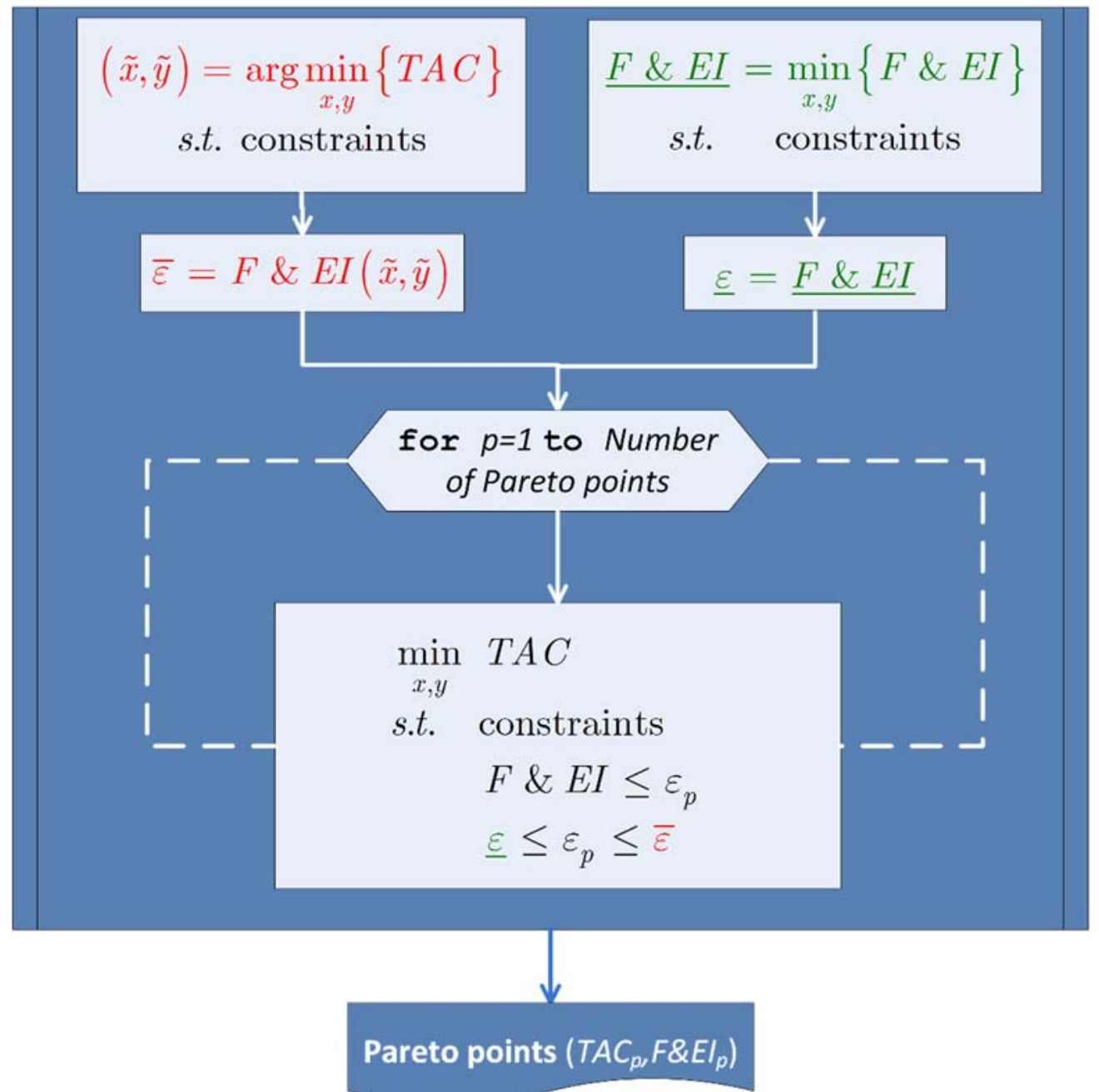

Figure 2. Algorithm to compute the Pareto frontier using the $\varepsilon$-constraint method for the biobjective (TAC and F\&EI) optimization problem. 


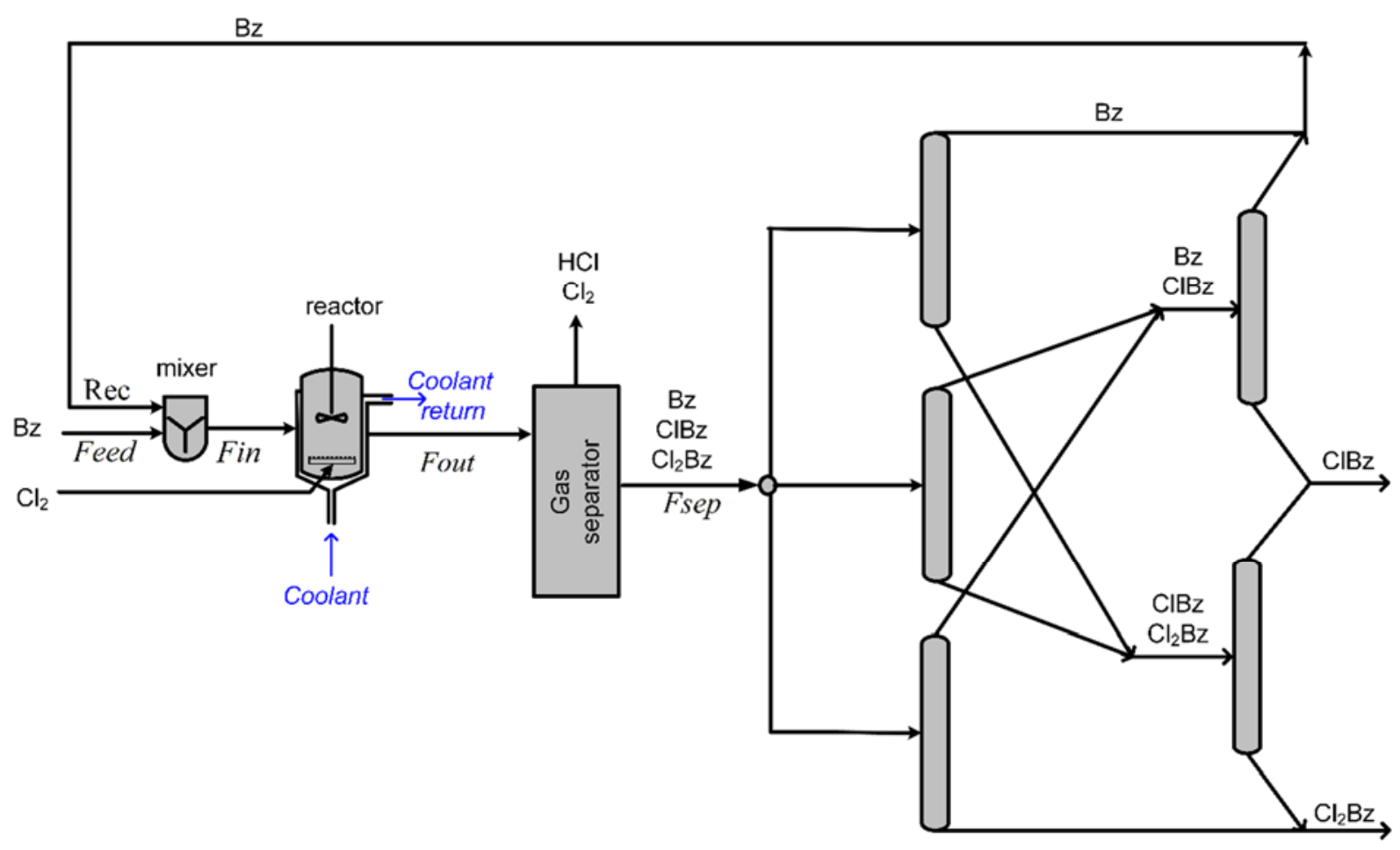

Figure 3. Proposed superstructure for the monochlorobenzene production. 


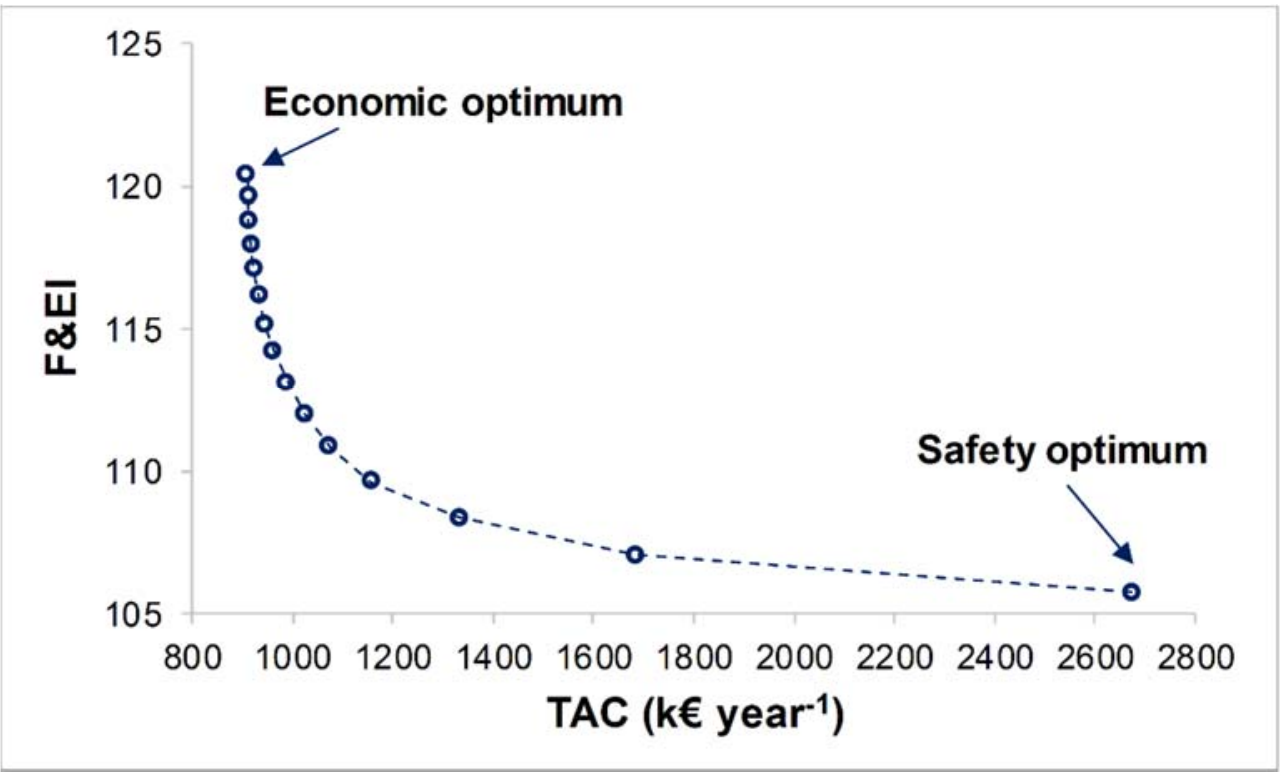

Figure 4. Pareto set of solutions for the monochlorobenzene production. 


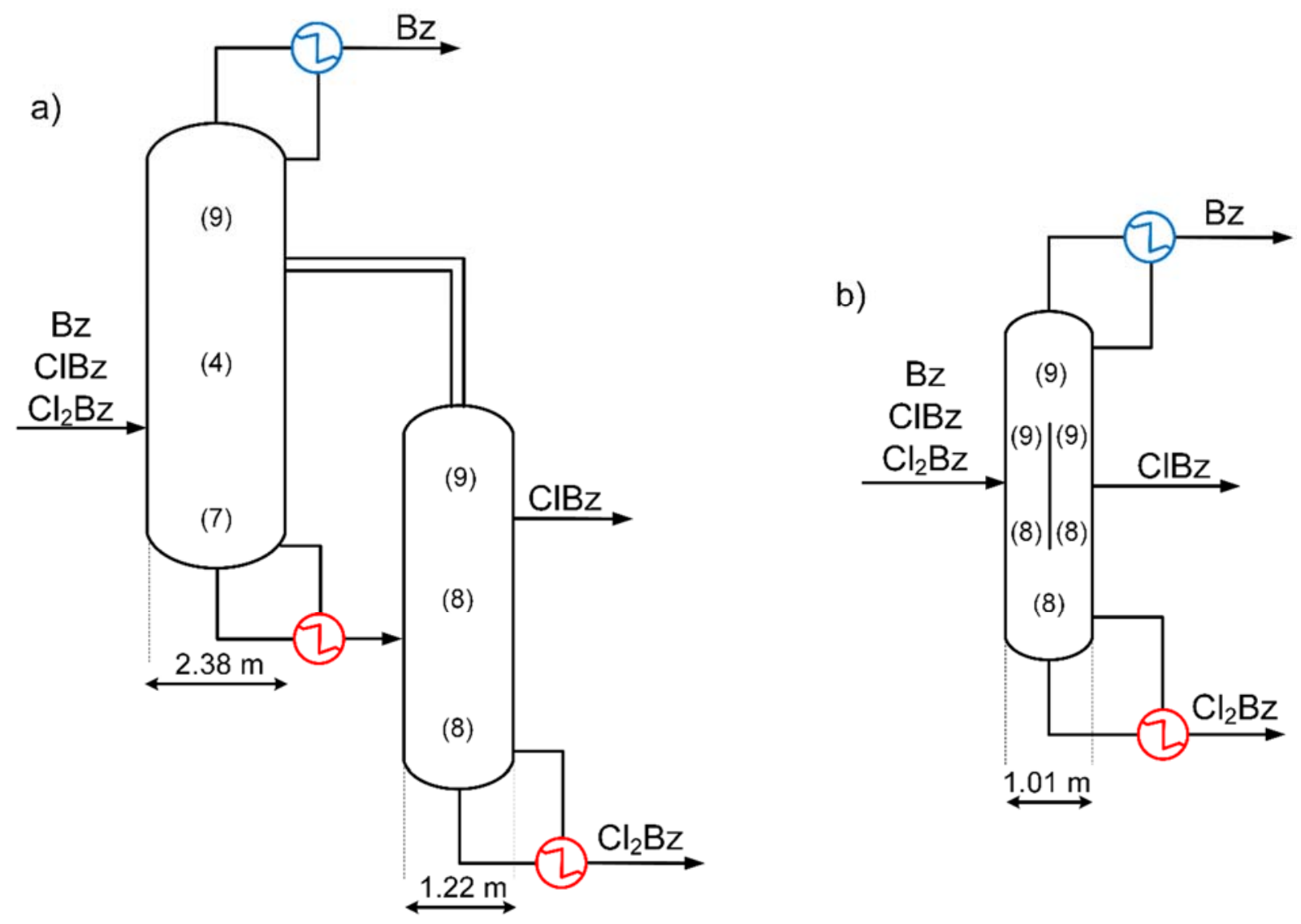

Figure 5. Optimal distillation sequence for the two extremes Pareto solutions: a) minimum F\&EI, a thermodynamic equivalent form of the prefractionator with thermocouple instead of condenser; b) minimum TAC, a Divided Wall Column (the numbers in brackets correspond to the number of trays in each section). 


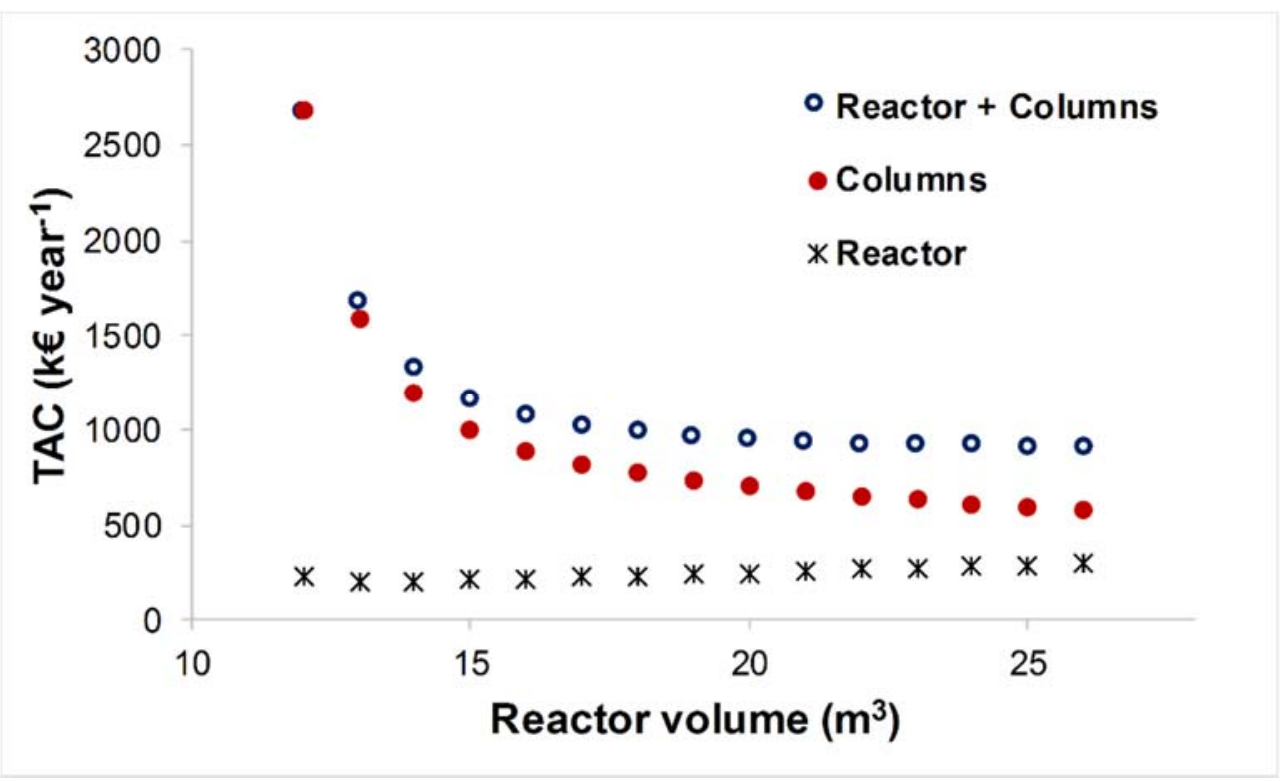

Figure 6. TAC for the main units as a function of the reactor volume. 


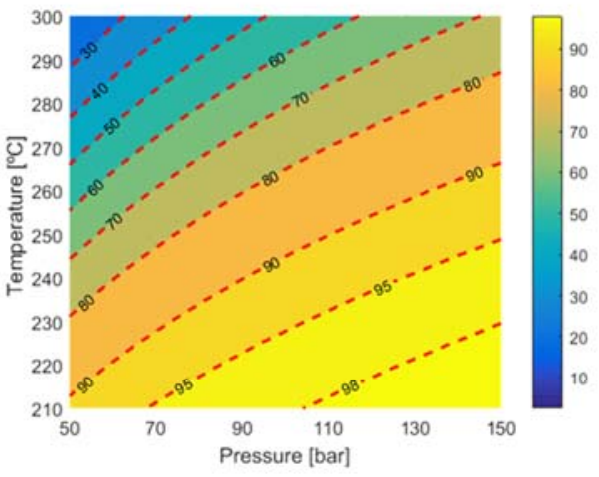

(a)

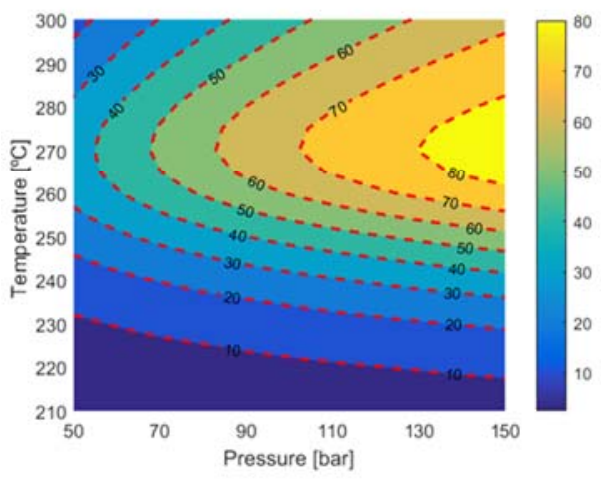

(b)

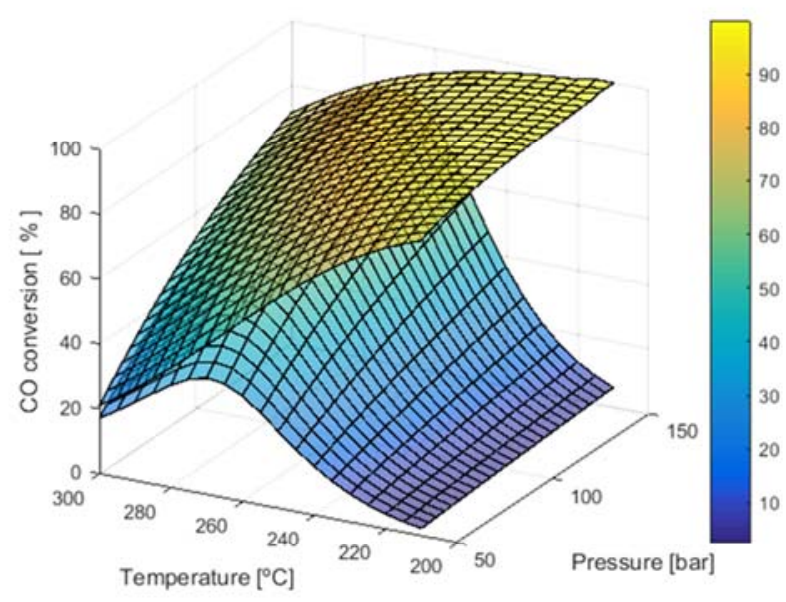

(c)

Figure 7. CO conversion as a function of pressure and temperature determined from: (a) equilibrium; (b) kinetics in an isothermal plug flow reactor with a residence time of 3 min; (c) both conversions overlaid in a surface plot. 


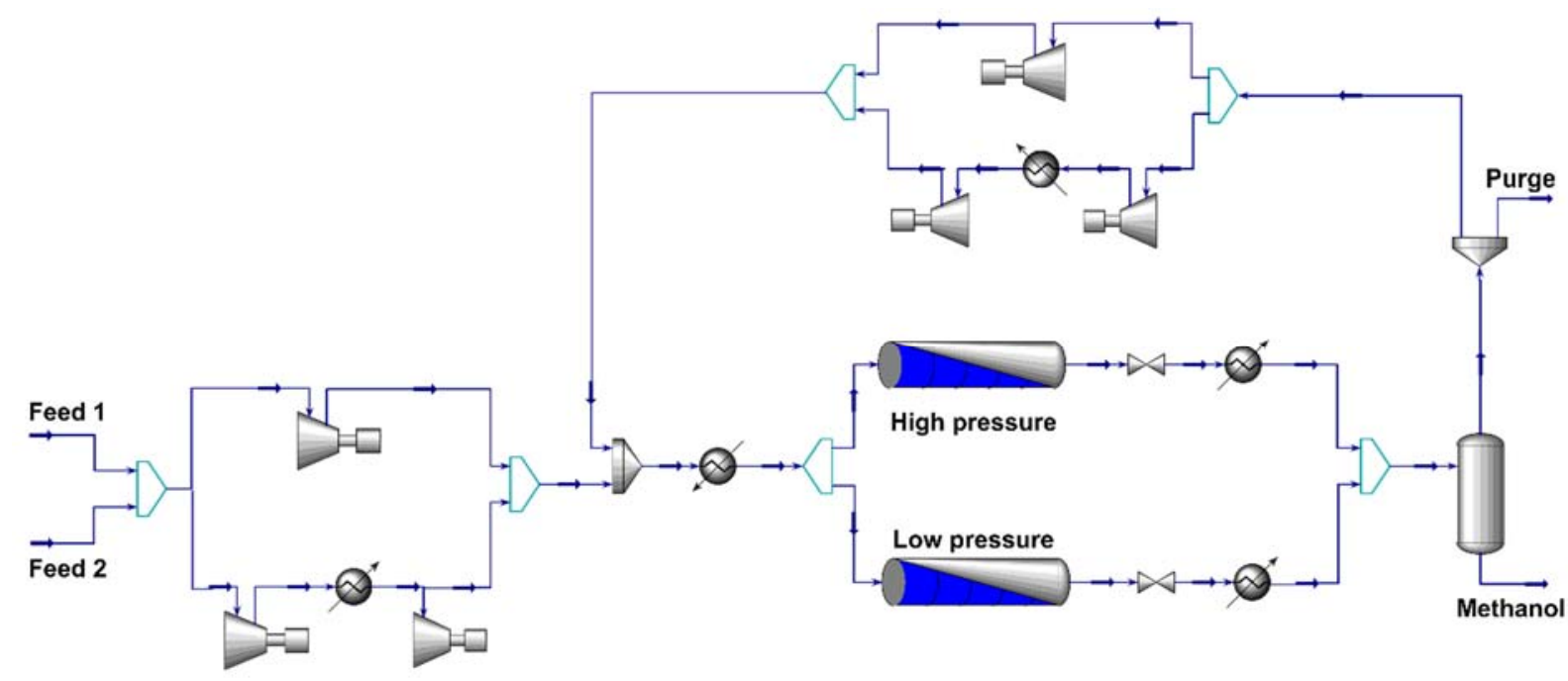

Figure 8. Superstructure that embeds the flowsheet alternatives for the reaction section of a methanol plant. 


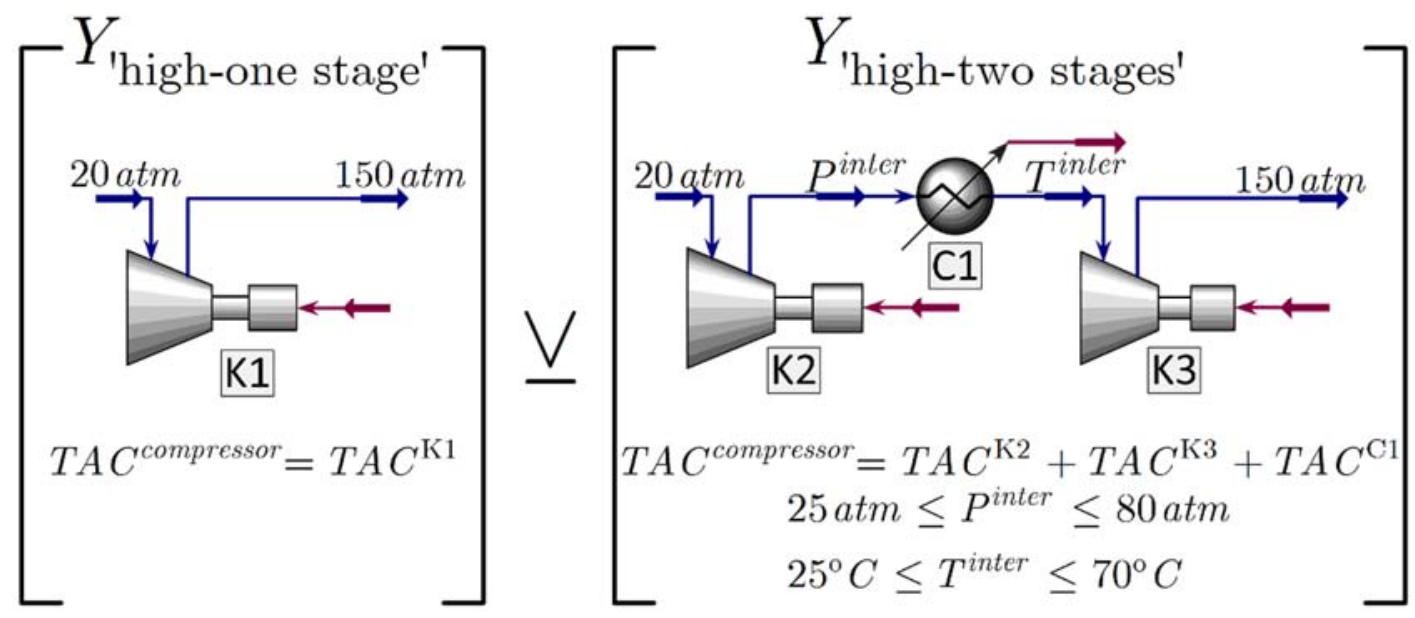

Figure 9. Disjunction for modelling the structural options for the compression feed block at the highest level of pressure (150 atm). 


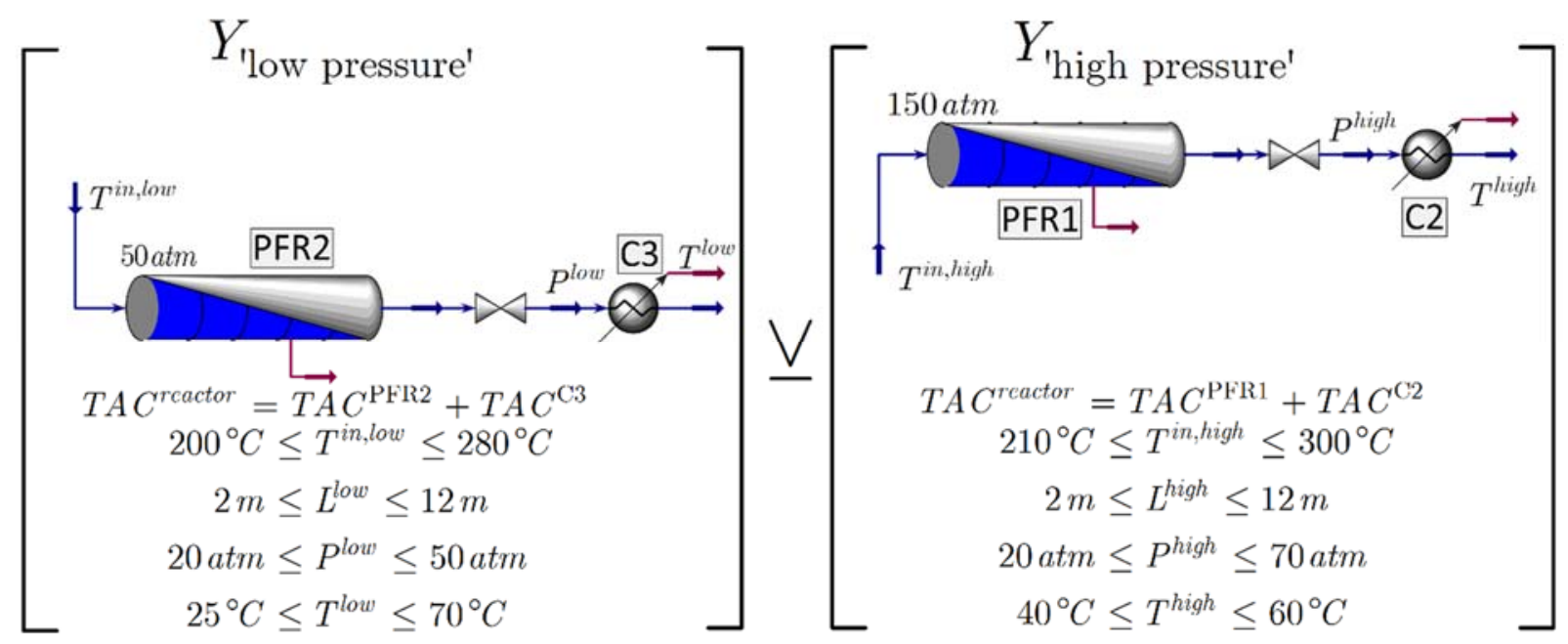

Figure 10. Disjunction that models the two alternatives for the reaction block of the superstructure, low and high pressure. 


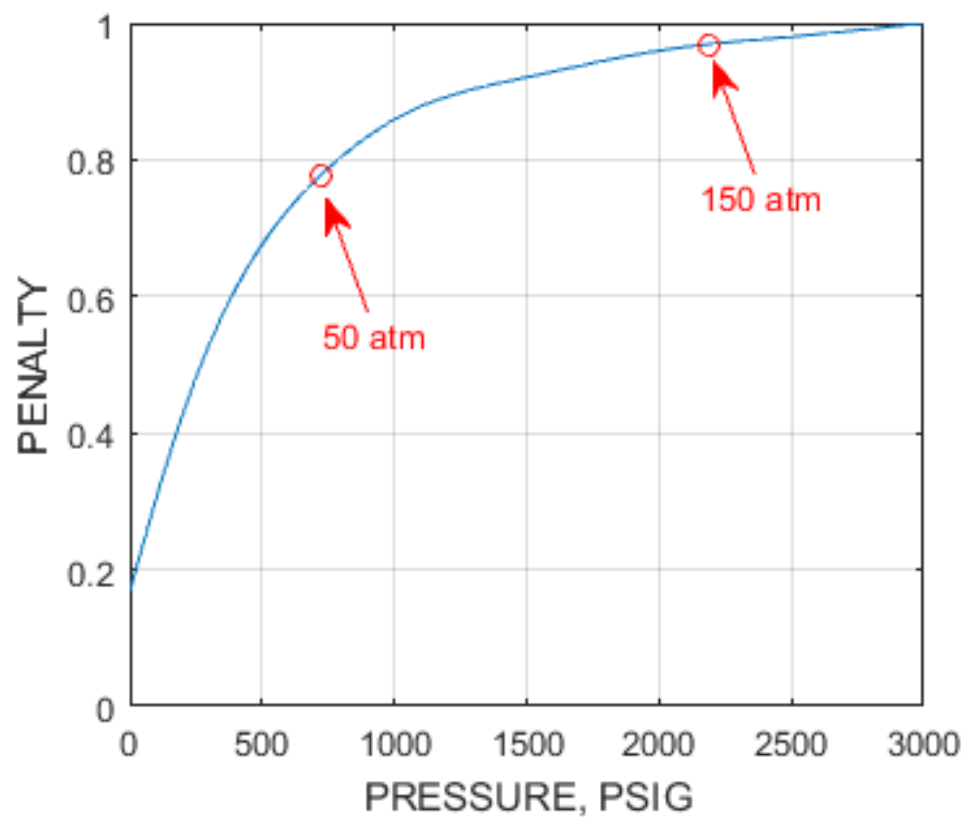

Figure 11. Pressure penalty correlation of the DOW's F\&EI modified to extend its domain for pressure higher than 1000 psig. 


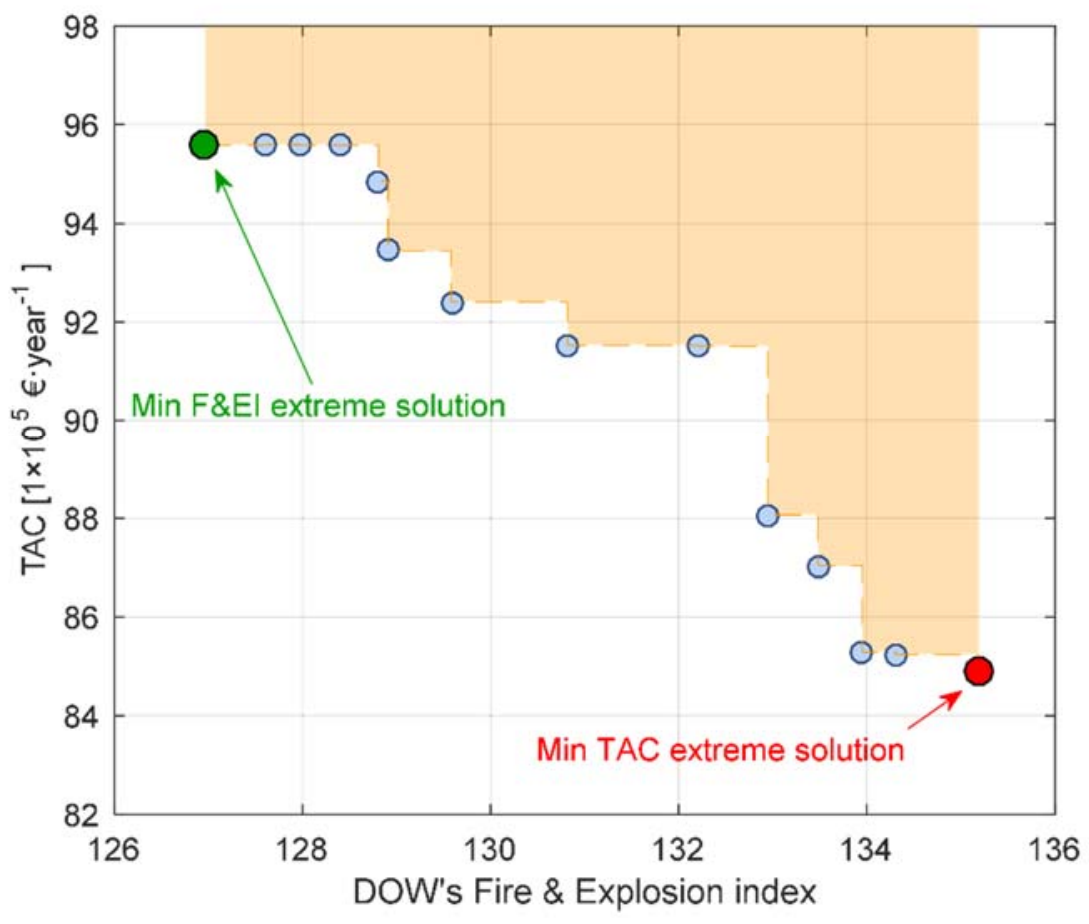

Figure 12. Pareto set of solutions for the bi-objective problem that minimizes the Total Annualized Cost (TAC) and the F\&EI for the methanol plant. 

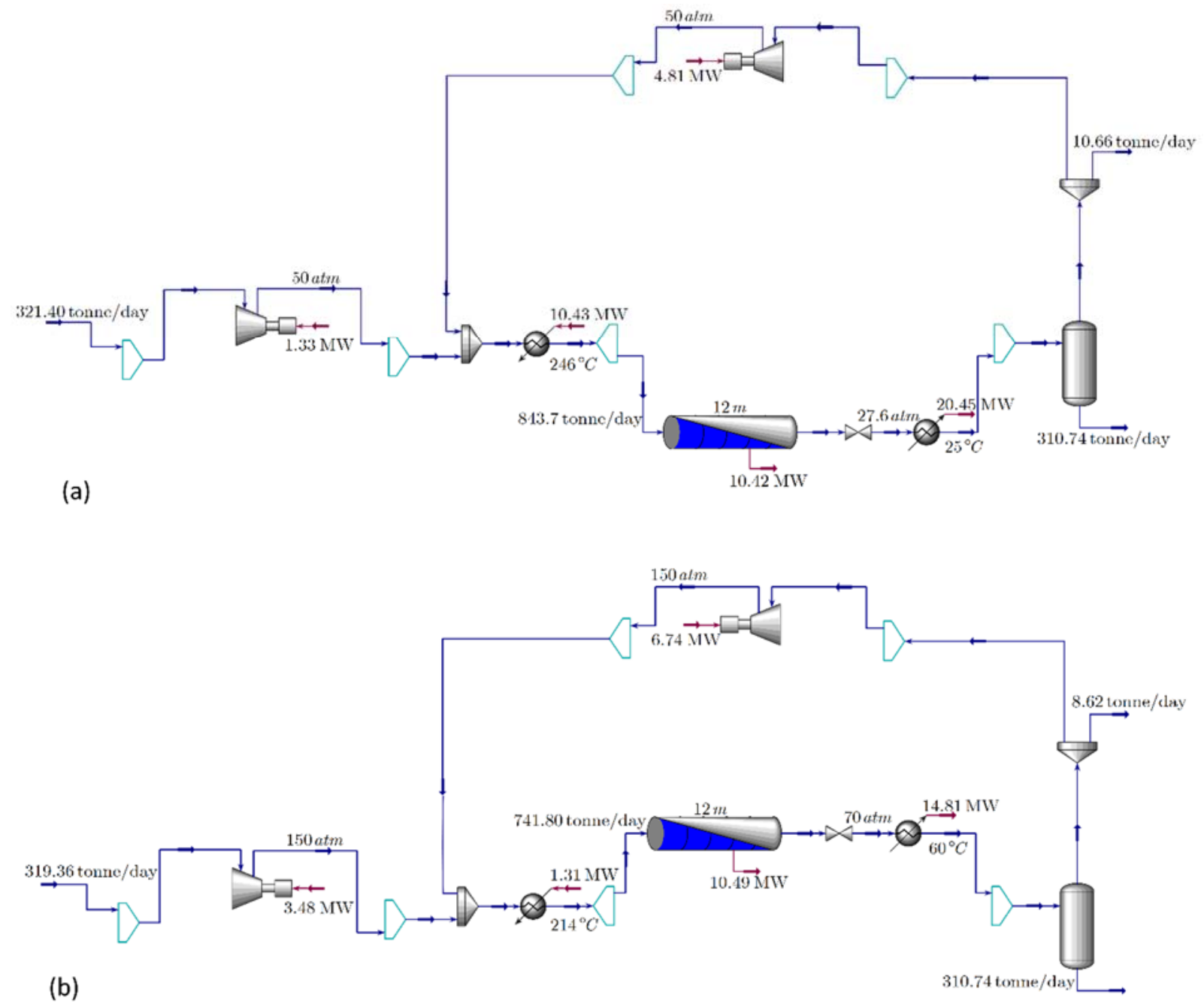

Figure 13. Flowsheet with the values for the main decision variables for the extreme solutions:

(a) minimum F\&EI; (b) minimum TAC. 


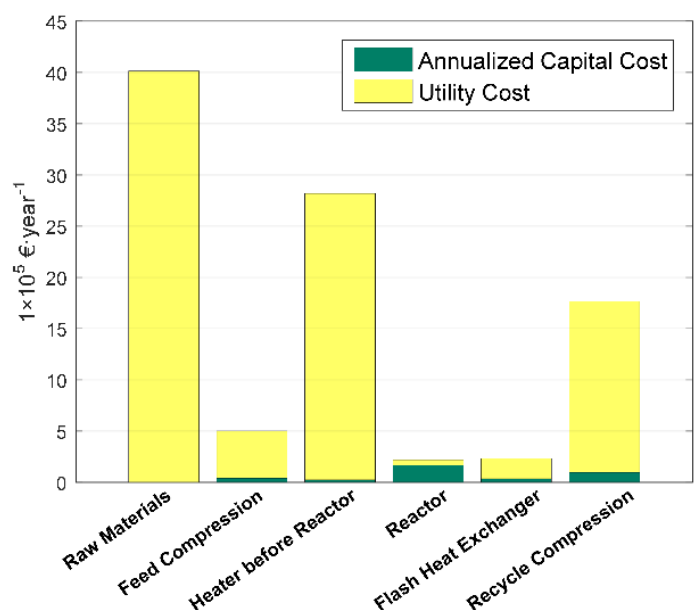

(a)

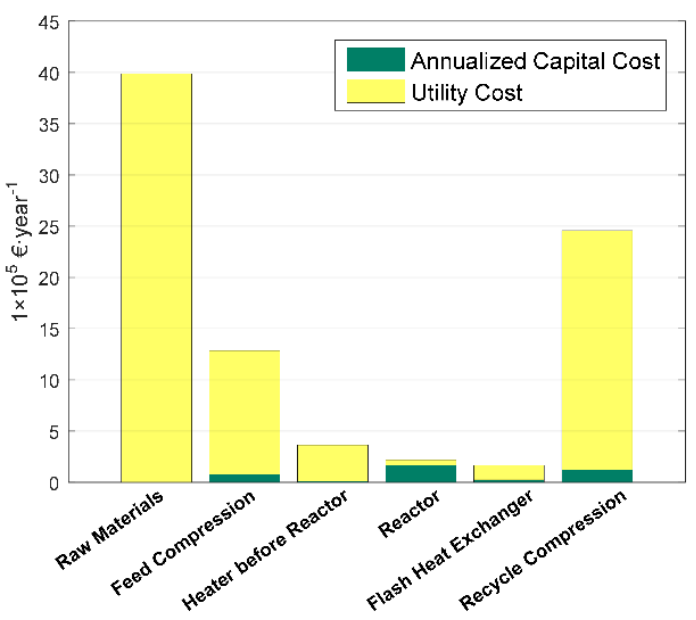

(b)

Figure 14. Distribution of the costs for the extreme solutions: (a) minimum F\&EI; (b) minim TAC. 


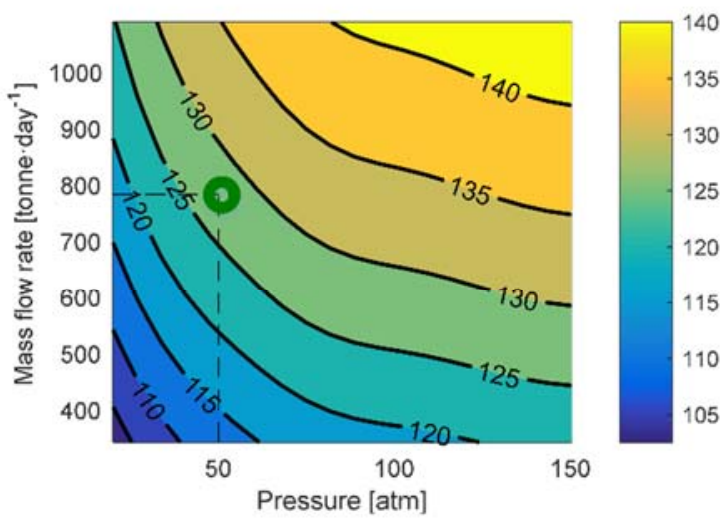

(a)

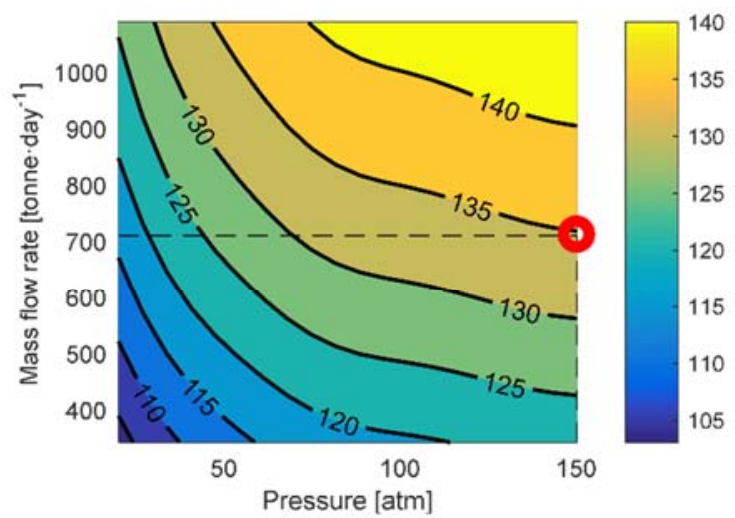

(b)

Figure 15. Dow's F\&EI contour plots for the extreme solutions: (a) minimum F\&EI; (b) minimum TAC. 


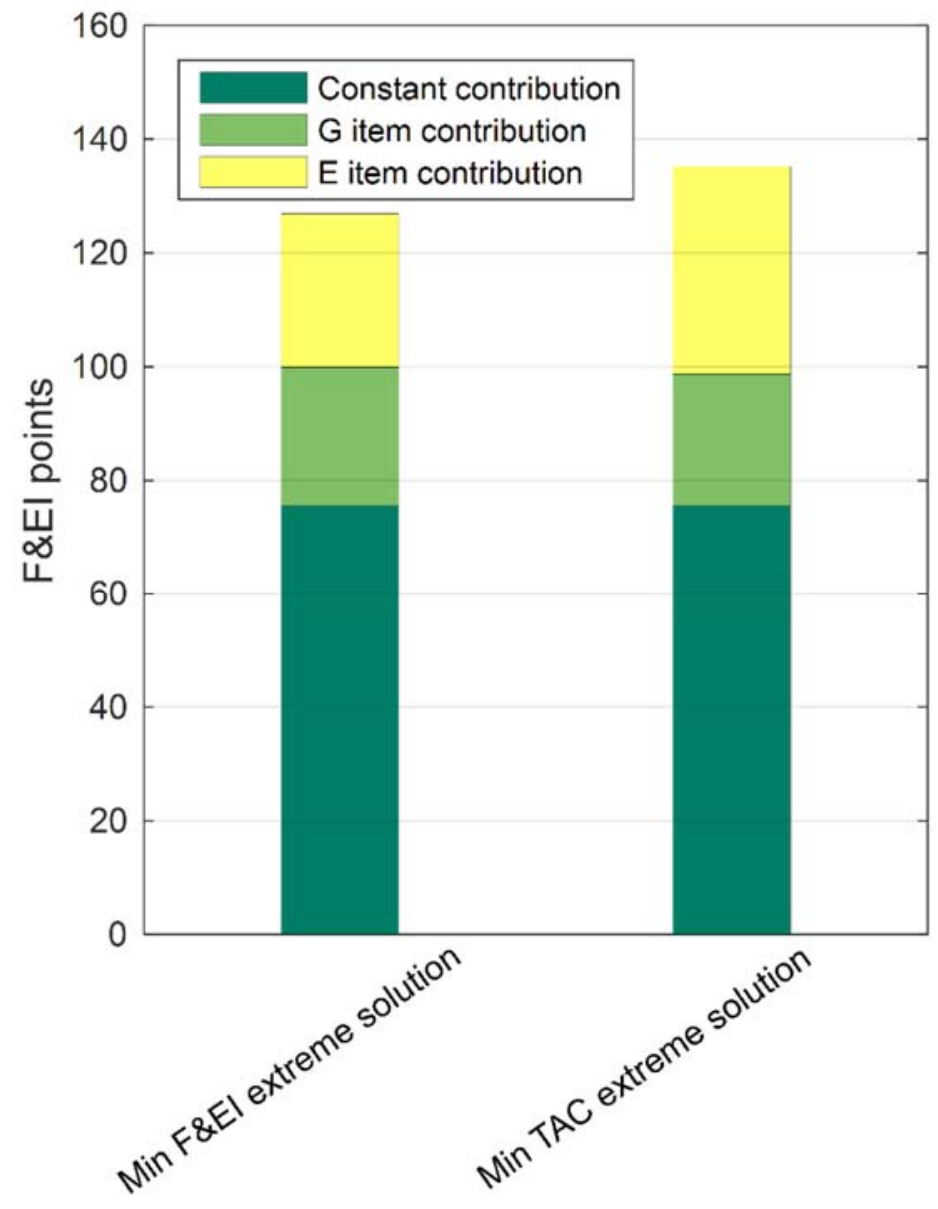

Figure 16. F\&EI split into the constant contribution and the contributions arising from each decision variable for both extreme solutions. 


\section{Graphical abstract}

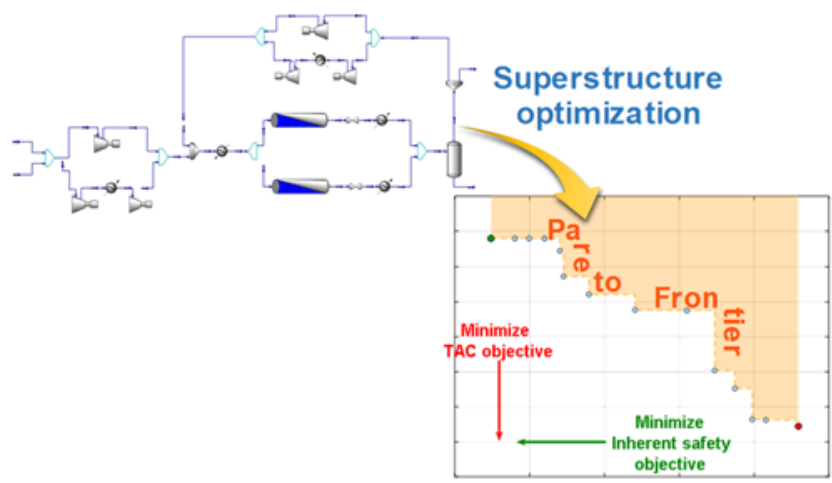

